\title{
Water-based routes for synthesis of metal-organic frameworks: A review
}

\author{
Chongxiong Duan ${ }^{1}$, Yi Yu ${ }^{2}$, Jing Xiao ${ }^{2}$, Xuelian Zhang ${ }^{2}$, Libo $\mathrm{Li}^{2}$, Pengfei Yang ${ }^{4}$, Junliang $\mathrm{Wu}^{3^{*}}$ and \\ Hongxia $\mathrm{Xi}^{2 *}$
}

\begin{abstract}
Although metal-organic frameworks (MOFs) show numerous advantages over other crystalline materials, their industrial relevances have been impeded owing to their many drawbacks such as environmental impacts and economic costs of their synthesis. A green preparation pathway could greatly reduce the environmental costs, energy, and the need for toxic organic solvents, and consequently reduce the production cost. Thus, the most desirable synthesis route is the replacement of harsh organic solvents with aqueous solutions to abate environmental and economic impacts. This review summarizes recent research advancements of water-based routes for MOF synthesis and gives a brief outline of the most prominent examples. The challenges and prospects of the commercialization of promising MOFs in the future are also presented. This study aims to offer necessary information regarding the green, sustainable, and industrially acceptable fabrication of MOFs for their commercial applications in the future.
\end{abstract}

Keywords: metal-organic frameworks, water-based routes, industrial production

\section{INTRODUCTION}

Metal-organic frameworks (MOFs) or porous coordination polymers (PCPs), constructed from organic ligands and inorganic building units (metal ions or clusters), are an intriguing class of coordination polymers [1-3]. There has been a substantial increase in interest of MOFs owing to their attractive physicochemical characteristics such as high surface area, permanent porosity, abundant active sites, and flexible chemical structure [4-9]. To date, the main focus of MOF investigations is the optimization of their structures or properties, such as increasing the crystallinity and pore size, to develop their potential applications in gas storage [10-13], adsorption and separation [14-17], large molecule encapsulation [18-20], supercapacitors [21-23], energy conversion [24,25], chemical sensors [26-28], biomedicine [29,30], and catalysis [31-33]. However, the synthesis conditions of MOFs for eco-friendly and industrial scale-up were only sparsely investigated in both research and industrial laboratories $[34,35]$. Usually, MOF syntheses involve solvothermal reactions of a solution containing metal salts and ligands in organic solvents (e.g., $N, N$-dimethylformamide (DMF), ethanol) or mixtures of organic solvents and water [3638]. In these processes, commonly employed organic solvents such as DMF increase the cost and pose safety and environmental risks $[39,40]$. Furthermore, some organic solvents easily decompose and generate large amounts of waste by-products, which influence the functions and properties of the desired product [41-43]. Although some organic solvents can be recycled and reused in some cases [44], the heavy use of hazardous and toxic solvents hinders the industrial and commercial feasibility of MOF application, from the environmental and economic perspectives [45-47]. Thus, the development of green synthetic route, wherever technically and economically practicable, to minimize the use of costly and toxic organic solvents in MOF synthesis, is a great challenge.

To date, tremendous efforts have been made to develop alternative methods to mitigate and/or eliminate the use and generation of hazardous organic solvents in the synthesis of MOFs [48-51], including solvent-free method [52], aerosol route [53], microwave irradiation and ultrasound-assisted techniques [54,55]. These ap-

\footnotetext{
${ }^{1}$ School of Materials Science and Energy Engineering, Foshan University, Foshan 528231, China

${ }^{2}$ School of Chemistry and Chemical Engineering, South China University of Technology, Guangzhou 510640, China

${ }^{3}$ School of Environment and Energy, South China University of Technology, Guangzhou 510006, China

${ }^{4}$ School of Chemistry and Chemical Engineering, University of South China, Hengyang 421001, China

* Corresponding authors (emails: ppjl@scut.edu.cn (Wu J); cehxxi@scut.edu.cn (Xi H))
} 
proaches not only avoid the use of hazardous solvents in the synthesis of MOFs, but also have advantages, such as excellent stability, tunable porosity, high production rate, and continuous production in the resulting MOFs $[56,57]$. However, these methods have low generality, and involve complicated synthetic procedures and equipment $[58,59]$. Therefore, it is urgent to develop a simple and general method for the green synthesis of MOFs without the use of organic solvents.

Water is considered to be the cleanest solvent for the synthesis of MOFs. Thus, one measure that can reduce the cost and boost the environmental friendliness is to use water as the reaction medium $[60,61]$. In comparison with organic solvents, water as a solvent to dissolve MOF precursors (metal salts and ligands) is non-toxic, stabe, cheap and easy to get and disposable [62]. Furthermore, the organic solvents trapped in the pore channels of MOFs are often difficult to fully eliminate while water can be easily removed [63], indicating that water-based synthesis conditions can lead to improved material properties. Most of MOFs that can be synthesized in water are stable in water, e.g., UiO-66, MIL-160 and CAU-10 MOFs $[13,43]$. Nevertheless, quite a few watersensitive MOFs, such as $\mathrm{Cu}_{3}(\mathrm{BTC})_{2}$, can also be synthesized in water [64], which might be attributed to the influence of organic co-solvent or the high temperature/ pressure during the synthesis which may stabilize MOFs in water (note the MOFs' stability in water is usually assessed at room temperature and ambient pressure) $[65,66]$. Based on previous reports [67], the addition of water contributes in one or more functions in the MOF synthesis: (1) as the reaction solvent to dissolve MOF precursors; (2) as an additive to realize a certain of function; (3) as both solvent and additive. Hence, the synthesis of MOFs in aqueous solutions not only reduces the manufacturing cost and addresses environment-related impacts, but also improves their structures and properties $[68,69]$. From a commercial perspective, although only a few MOFs have been utilized in practical applications, the use of clean and renewable water as solvents to save costs, while avoiding contamination of water, can be considered as a pivotal benefit for an industrial scale production $[45,60,70]$. Moreover, from an academic perspective, water-based synthesis conditions are also significant since they represent a new research field which may provide a direction to synthesize new materials with outstanding structures and properties [71,72].

Generally, the water-based synthesis of MOFs refers to the use of water as a reaction solvent [73]. Although or- ganic additives usually are also used, their dosages are (much) smaller than water. For example, Li et al. [74] reported the water-based synthesis of mesoporous $\mathrm{Zr}$ based MOFs templated by amphoteric surfactants, where the molar composition of the cocamidopropyl betaine (CAPB) and water $\left(\mathrm{H}_{2} \mathrm{O}\right)$ was $0.438 \mathrm{CAPB}: 282 \mathrm{H}_{2} \mathrm{O}$, which accords with the concept of water-based synthesis. To date, many excellent reviews have been summarized for the green synthesis of MOFs based on low-energy (e.g., room temperature and ambient pressure) and high production rate $[45,62,70,75-78]$. However, to the best of our knowledge, there lacks specialized review for the waterbased synthesis route of MOFs that offers the necessary information regarding their synthesis mechanisms as well as merits and demerits of different routes. Based on the advantages of water-based synthesis of MOFs as stated above, we will describe in detail the various routes and methods developed during the last ten years for the water-based synthesis of MOFs, and will focus on their synthesis mechanisms, as well as merits and demerits of various methods.

\section{DIFFERENT TYPES OF MOFs SYNTHESIZED IN AQUEOUS SYSTEMS}

A remarkable feature of MOFs is the wide diversity of their topological structures. Currently, over 80,000 MOFs have been synthesized (based on the Cambridge Structural Database) [79], but an uniform classification has not yet been achieved. At present, only a limited number of MOFs have been synthesized in water, though the number should grow quickly. We will focus on the most representative MOFs which have been synthesized in water and have shown wide impact, such as zeolitic imidazolate frameworks (ZIFs), isoreticular MOFs (IRMOFs), MIL, $\mathrm{UiO}$, coordination pillared-layer (CPL), and porous coordination network (PCN). We do not aim to comprehensively review thousands of MOFs herein, for which the readers could refer to other recent excellent reviews $[70,80-83]$.

\section{ZIF series}

ZIFs comprises transition metals (Zn or Co) and imidazolate-based ligands and are a subfamily of porous MOFs with a sodalite-type cage similar to zeolites $[84,85]$. They organically combine the merits of MOFs and zeolites, including high surface area, tunable surface properties, and excellent thermal and chemical stability $[86,87]$. These properties make them a worthwhile potential candidate for a large variety of industrial applications.

Recently, several investigations have been performed on 
the synthesis of ZIFs under water-based conditions. The first example of ZIF materials synthesized in an aqueous solution was reported by Pan et al. [88], who prepared ZIF-8 crystals in an aqueous system at room temperature in a short time ( $\sim 5 \mathrm{~min})$ with a high product yield of $80 \%$ (based on the amount of $\mathrm{Zn}$ ) using excess ligand (2methylimidazole, 2-MI). The resulting ZIF-8 products possessed small crystal sizes with a diameter of $\sim 85 \mathrm{~nm}$ and excellent thermal, chemical, and hydrothermal stabilities (Fig. 1). Moreover, Pan et al. [89] presented the preparation of ZIF-8 in an aqueous solution and controlled the size and morphology of crystals, using cetyltrimethylammonium bromide (CTAB) as a capping agent. For example, the crystal sizes of ZIF-8 can be tuned from micrometer to nanometer and the morphology changed from rhombic dodecahedron (RD) to truncated rhombic dodecahedron (TRD) to truncated cubic, by controlling the amount of CTAB. This can be attributed to the long hydrophobic hydrocarbon chain of $\mathrm{CTAB}$ adsorbed on the hydrophobic surface of the ZIF-8 crystals, thereby functioning as capping agents to slow down the crystal growth rate. However, no research has examined the mechanism of ZIF-8 synthesis in aqueous solutions. Although CTAB was added into the synthesis system, this organic additive was used as a modulator to reduce ZIF crystal growth rate rather than being used as a reaction solvent. Therefore, the addition of certain organic additives into the MOF preparation system still remains consistent with the theme of water-based synthesis.

Kida et al. [90] reported another example of ZIF-8 synthesized in an aqueous system using different molar ratios of $2-\mathrm{MI} / \mathrm{Zn}$ at room temperature. At high molar ratios of 2-MI/Zn, the obtained ZIF-8 product exhibited a $\mathrm{RD}$ shape and possessed ultrahigh surface areas and micropore volumes. When the molar ratio of $2-\mathrm{MI} / \mathrm{Zn}$ was low, some by-products such as zinc hydroxide and basic zinc nitrate appeared in the ZIF- 8 crystals. These results showed the influence of the concentration of 2-MI on the crystallization, morphology, particle size, and purity of ZIF-8 crystals. Specifically, the formation process of ZIF-8 crystals in an aqueous solution was investigated, where the high $\mathrm{pH}$ conditions enabled the deprotonation of 2MI and accelerated the formation of ZIF-8 crystal. Therefore, water-based synthesis of ZIFs without extra additives is required for an excess amount of organic ligands. However, the excessive ligand used during the synthesis is unfavorable from the economic and environmental perspectives [91].

Some auxiliary substances such as triethylamine (TEA), sorbitan monooleate (Span) 80, and polyoxyethylene sorbitan monooleate (Tween) 80 can be used as a modulator to accelerate ZIF crystallization in aqueous systems. For example, Gross et al. [92] reported the waterbased synthesis of ZIF- 8 and ZIF-67 within 10 min at room temperature and ambient pressure by using TEA as a protonation agent. The results indicate that the introduction of TEA can deprotonate the ligand of 2-MI and initiate the nucleation of ZIF materials. More importantly, the inherent 2 -MI can act as a structure directing agent (SDA) and function as an organic solvent [93], thereby resulting in the ZIF synthesis in aqueous solutions. In addition, the added TEA and ligand may also be reused in a scaled-up synthesis in industrial production. Subsequently, Nordin et al. [94] reported the influences of TEA on the crystallinity of ZIF- 8 crystals in an aqueous system. As shown in Fig. 2, ZIF-8 crystals cannot form when the TEA/total molar ratio is below 0.004 . However, the produced ZIF- 8 crystals are in a pure phase as the TEA/total molar ratio is further increased from 0.004 to 0.007 . When the TEA/total molar ratio exceeds 0.007 , impure crystals are formed. In addition, Fan et al. [95] prepared pure ZIF-8 crystals in an aqueous solution by introducing Span 80 and Tween 80 as mod-
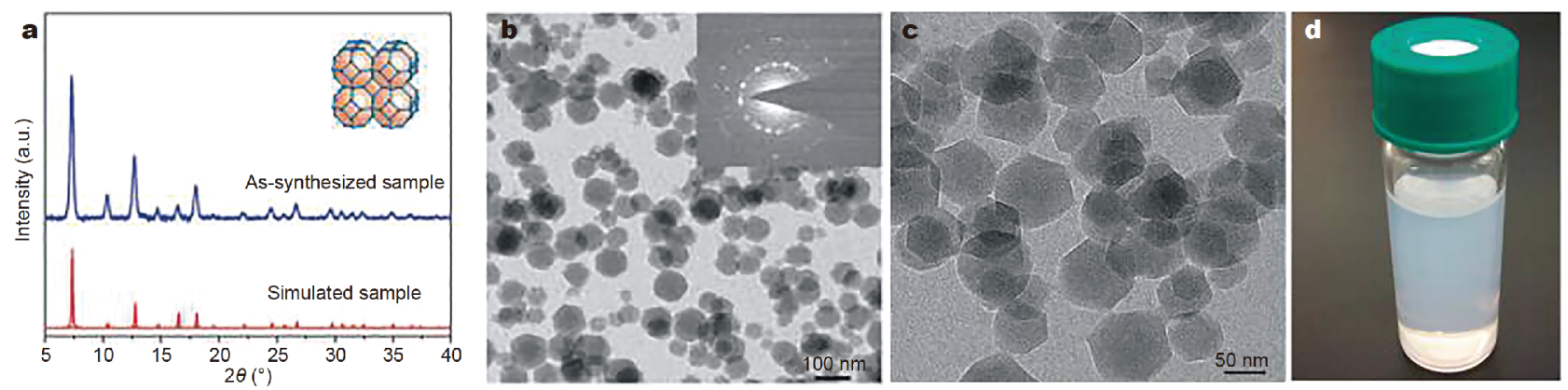

Figure 1 (a) XRD patterns and (b, c) TEM images of ZIF-8 synthesized in an aqueous solution; (d) photograph of the as-synthesized ZIF-8 dispersed in methanol. Reprinted with permission from Ref. [88]. Copyright 2011, Royal Society of Chemistry. 


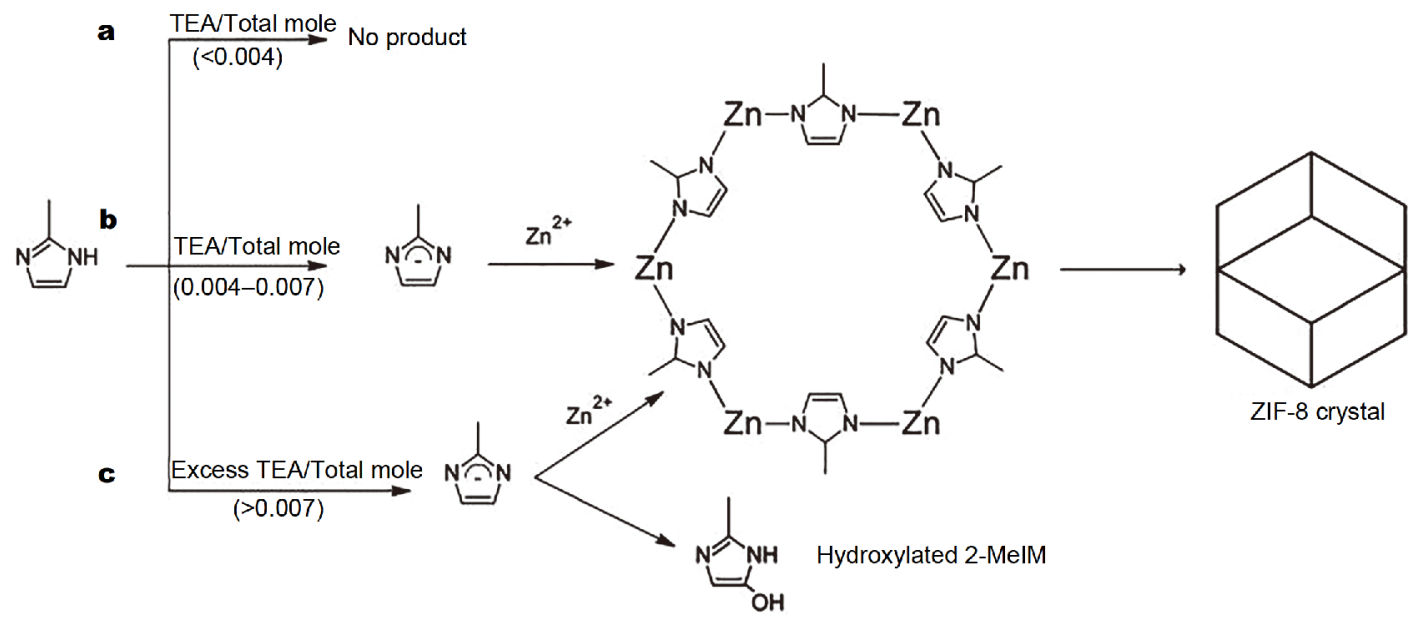

d

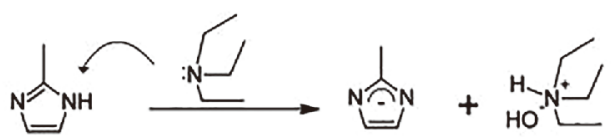

Figure 2 Illustration of the influence of TEA concentration on the ZIF-8 formation in aqueous systems. Reprinted with permission from Ref. [94]. Copyright 2014, Royal Society of Chemistry.

ulators to ensure that the $\mathrm{Zn}-2-\mathrm{MI}$ coordination structure is free of $\mathrm{H}_{2} \mathrm{O}$ and $\mathrm{OH}^{-}$attack, thereby obtaining pure ZIF-8 crystals in the aqueous solution at low $2-\mathrm{MI} / \mathrm{Zn}$ ratio.

Other than conventional ZIF materials that contain one metal ion, emerging ZIFs known as mix-metal ZIFs with at least two different metals can also be obtained in an aqueous solution. Recently, Kaur et al. [96] reported the preparation of bimetallic Co-Zn based ZIFs (CoZn-ZIF$8)$ in an aqueous system at room temperature. They synthesized robust bimetallic CoZn-ZIF-8 by mixing cobalt nitrate hexahydrate, zinc nitrate hexahydrate, and 2-MI in water and then stirring the solution for $10 \mathrm{~min}$ (Fig. 3). The results of powder X-ray diffraction (PXRD) and electron microscopy (scanning electron microscopy (SEM) and transmission electron microscopy (TEM)) indicate that Co was incorporated into the Zn-ZIF-8 crystal without breaking or transforming the framework. Furthermore, the content of Co and $\mathrm{Zn}$ in the CoZn-ZIF8 can be effectively tuned by controlling the amounts of $\mathrm{Co}$ and $\mathrm{Zn}$ precursors. However, some issues still require further studies, such as the mechanism of inserting Co into Zn-ZIF-8 crystal and the random distribution or aggregation of a certain metal over the metal node [1,97].

\section{IRMOF series}

IRMOFs comprise linear organic ligands (e.g., dicarboxylic acid and tricarboxylic acid) and metal ions or

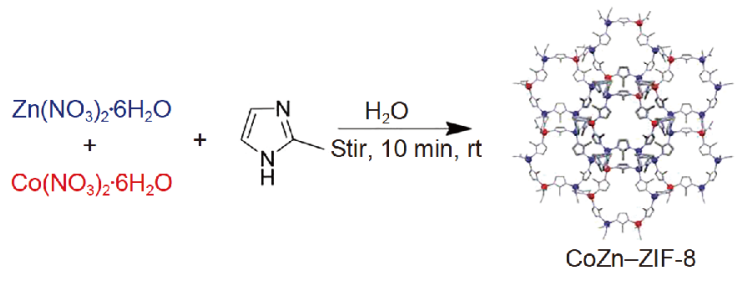

Figure 3 Schematic of the room-temperature synthesis of CoZn-ZIF-8 in aqueous solution. Reprinted with permission from Ref. [96]. Copyright 2016, Royal Society of Chemistry.

clusters and are a subclass of MOFs [98]. They usually share a common net topology such as cubic topology [99]. Over the past decades, several typical IRMOFs, such as MOF-5, MOF-74, MOF-177, and MOF-199 (HKUST-1 or $\mathrm{Cu}-\mathrm{BTC})$, have been widely studied $[99,100]$. However, most IRMOFs are synthesized in organic solvent systems [101]; only a few IRMOFs are synthesized in aqueous systems.

HKUST-1 is instable upon exposure to water or even moist environment, because the metal-oxygen coordination of HKUST-1 is vulnerable to water molecule attacks [65]. However, HKUST-1 can be synthesized in an aqueous solution. Huo et al. [102] proposed a novel facile and rapid room-temperature synthesis approach to prepare HKUST-1 through vigorous mixing of metal salt powder (cupric acetate anhydrous, $\mathrm{Cu}(\mathrm{OAC})_{2}$ ) with excess ligand (benzene-1,3,5-tricarboxylic acid, $\mathrm{H}_{3} \mathrm{BTC}$ ) using only 
water as the reaction solvent (Fig. 4). The crystallite size and porosity property of the MOF-199 product can be tuned by modulating the copper source and the reaction time, respectively. Moreover, the synthesis can be readily scaled-up so that the obtained MOF-199 possesses a high space-time yield (STY, $>2000 \mathrm{~kg} \mathrm{~m}^{-3}$ per day) owing to the clean reaction medium (water) and the reduced crystallization time $(<1 \mathrm{~h})$. However, during the purification procedure of crude MOFs ("activation"), unreacted $\mathrm{H}_{3} \mathrm{BTC}$ is removed using ethanol; therefore, the organic solvents have not been completely obviated from the overall process. Siew et al. [103] used very small amount of methanol to replace ethanol during the solvent activation process of MOF-199 (Cu-BTC) synthesis. Moreover, Majano et al. [104] used aqueous ethanolic solution as a solvent to prepare HKUST-1. Although the optimized synthesis route can reduce the amount of organic solvents, the method developed herein is not a complete water-based synthesis procedure. In addition, a more recent report described the preparation of MOF199 (Cu-BTC) crystals with only water as the solvent and excess methylamine as additive [105]. The synthesis time could be shortened to $5 \mathrm{~min}$ to achieve a product yield of $89 \%$. Although the activation process of MOF-199 was performed in distilled water, the introduction of methylamine in the synthesis process did not fully eliminate the use of costly and harmful organic solvents from the overall process. These results indicate that the water stability and the water-based synthesis conditions of MOFs are not correlated.

In addition to MOF-199 materials, other IRMOFs, such as MOF-74 can also be synthesized in water. Cadot et al. [51] reported the water-based synthesis of MOF-74-Ni by mixing a nickel $(\mathrm{Ni})$ precursor solution with a suspension of 2,5-dihydroxyterephthalic acid $\left(\mathrm{H}_{4} \mathrm{dhtp}\right)$ at high temperature. Moreover, Garzón-Tovar et al. [73] optimized this synthesis route under similar reaction conditions to obtain a series of MOF-74 based on $\mathrm{Mg}, \mathrm{Ni}, \mathrm{Co}$, and $\mathrm{Zn}$ in water without the need for heating (room temperature). The as-synthesized MOF-74-M materials have excellent Brunauer-Emmett-Teller (BET) surface areas $\left(>1200 \mathrm{~m}^{2} \mathrm{~g}^{-1}\right)$ and unprecedented STYs $\left(18,720 \mathrm{~kg} \mathrm{~m}^{-3}\right.$ per day). Recently, Didriksen et al. [106] developed a continuous-flow synthesis method for the preparation of MOF-74-Ni in a simple tubular reactor system using only water as the solvent (Fig. 5). At the optimal running conditions, a conversion above $90 \%$ can be reached in $\sim 20$ min. Besides, the obtained MOF-74-Ni product has high crystallinity and BET surface area. In addition, Julien et al. [107] developed a mechanochemical approach for preparing MOF-74-Zn by ball-milling a mixture of zinc oxide $(\mathrm{ZnO})$, dihydroxyterephthalic acid $\left(\mathrm{H}_{4} \mathrm{dhta}\right)$, and a small amount of water. This synthesis can be scaled to gram-scale $(2.7 \mathrm{~g})$, and the porosity properties of resulting products can reach a degree of product synthesized by a conventional method. These methods give a blueprint for the green and continuous synthesis of MOFs and hopefully achieve the industrial production.

\section{MIL series}

MIL is one kind of a few stable MOFs which could be thermally stable up to $>300^{\circ} \mathrm{C}$ in air and remain stable even after exposure to boiling water for weeks [108]. MIL-53 series are typical MIL MOFs that can be readily tuned while maintaining their intrinsic frameworks by employing different metal sources (e.g., $\mathrm{Al}, \mathrm{Fe}, \mathrm{Ga}$, and Sc) and/or BDC ${ }^{2-}$ (benzene-1,4-dicarboxylate) derivatives (e.g., amino, chlorine, fluorine, hydroxyl, nitro and carbamate) [109-112]. To date, MIL-53(Al) series synthesized in water have been intensively studied due to their excellent thermal stability and structural "breathing effect" $[113,114]$. The first example of MIL-53(Al) prepared

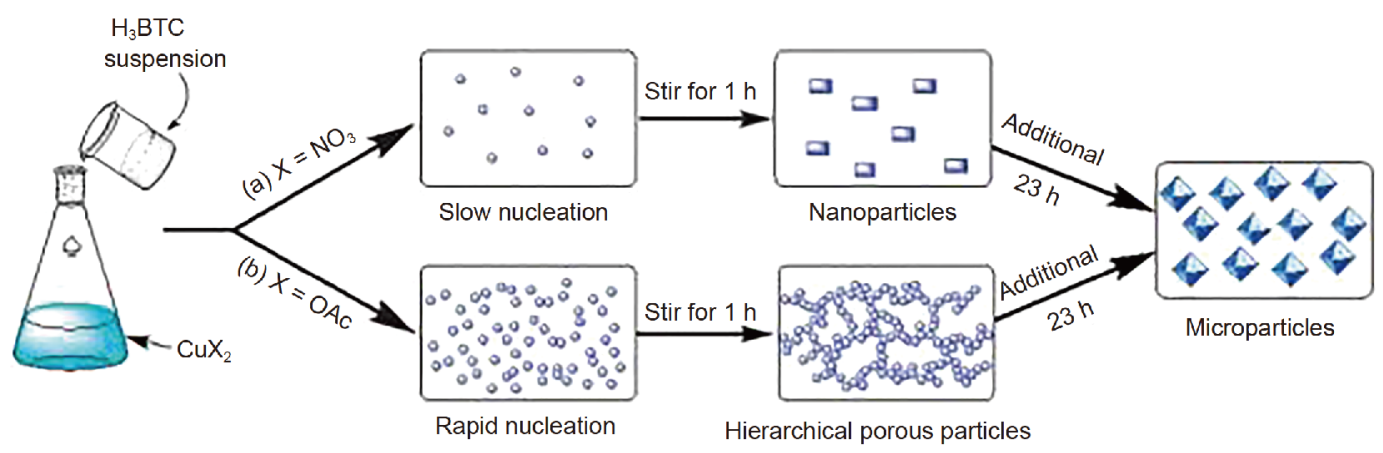

Figure 4 Schematic diagram of MOF-199 (HKUST-1) synthesis from a wholly aqueous reaction mixture. Reprinted with permission from Ref. [102]. Copyright 2013, Royal Society of Chemistry. 


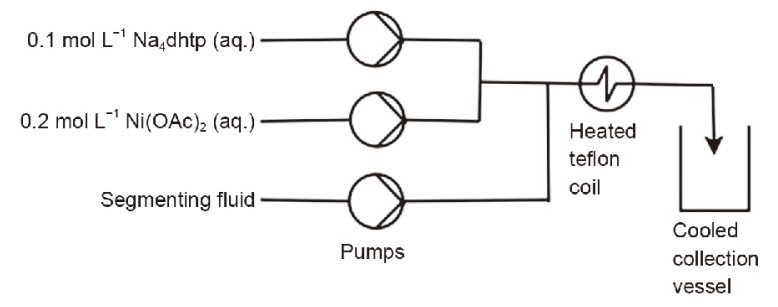

Figure 5 Schematic of the flow reactor system for MOF-74-Ni production. Reprinted with permission from Ref. [106]. Copyright 2018, Springer.

in an aqueous solution was reported by Cheng et al. [115] who developed a simple solvothermal method to synthesize $\mathrm{NH}_{2}-\mathrm{MIL}-53(\mathrm{Al})$ nanocrystals by varying the ratio of water in DMF-water mixed solvents. As shown in Fig. 6, the synthesis procedure could be improved by controlling the solvent conditions from DMF to water. When DMF is used as the only solvent, the ligand $\left(\mathrm{NH}_{2}-\right.$ BDC) can be rapidly deprotonated, thereby facilitating the formation of spherical crystals through the aggregation of numerous small particles. When a tiny amount of water is added to DMF as a mixed solvent, it can accelerate the rates of deprotonation and nucleation, thereby resulting in the formation of smaller crystals. As the water content is further increased, the excess water reduces the solubility of $\mathrm{NH}_{2}-\mathrm{BDC}$ and hinders the deprotonation of ligand, thereby slowing down the nucleation rate of crystals. Meanwhile, the introduced water can modulate the growth direction of the crystal. Therefore, the assynthesized $\mathrm{NH}_{2}-\mathrm{MIL}-53(\mathrm{Al})$ crystals exhibited a large and long rhomboid structure when pure water is used as a solvent. Furthermore, the obtained product synthesized in pure water possesses a very high crystallinity, BET surface area, pore volume and yield $(\sim 100 \%)$. Although this work involves the preparation of $\mathrm{NH}_{2}-\mathrm{MIL}-53(\mathrm{Al})$ in DMF, a pure water-based synthesis was reported.

Another example for the water-based synthesis of $\mathrm{NH}_{2}-$ MIL-53(Al) was reported by Guan et al. [116], who developed a facile route for the room-temperature synthesis of nano-sized $\mathrm{NH}_{2}-\mathrm{MIL}-53(\mathrm{Al})$ particles using a longstanding magnetic stirring. TEM images revealed the short rod-like morphology of the $\mathrm{NH}_{2}-\mathrm{MIL}-53(\mathrm{Al})$, which is different from the irregular shape of $\mathrm{NH}_{2}-$ MIL53(Al) synthesized in DMF. Moreover, the length and breadth of $\mathrm{NH}_{2}-\mathrm{MIL}-53(\mathrm{Al})$ obtained from water were less than 100 and $50 \mathrm{~nm}$, while the particles synthesized in DMF solvent ranged from dozens to hundreds of nanometers. Since the synthesis was conducted in an aqueous solution which altered the surface properties of MOFs, the as-synthesized $\mathrm{NH}_{2}-\mathrm{MIL}-53(\mathrm{Al})$ nanocrystals exhibited enhanced efficiency for removal of methyl blue from water compared with those prepared in DMF solvents using a conventional hydrothermal method [117]. Similarly, Jung et al. [118] reported aluminum-succinic acid (Al-SA) MOF synthesized in an aqueous solution. The as-synthesized Al-SA MOF exhibited an exceptional affinity toward Acid Black 1 (AB1) and fast removal of the substrate with the theoretical maximum uptake of $739.3 \mathrm{mg} \mathrm{g}^{-1}$, which was much higher than that of commercial powder-activated carbon (PAC). In addition, re-

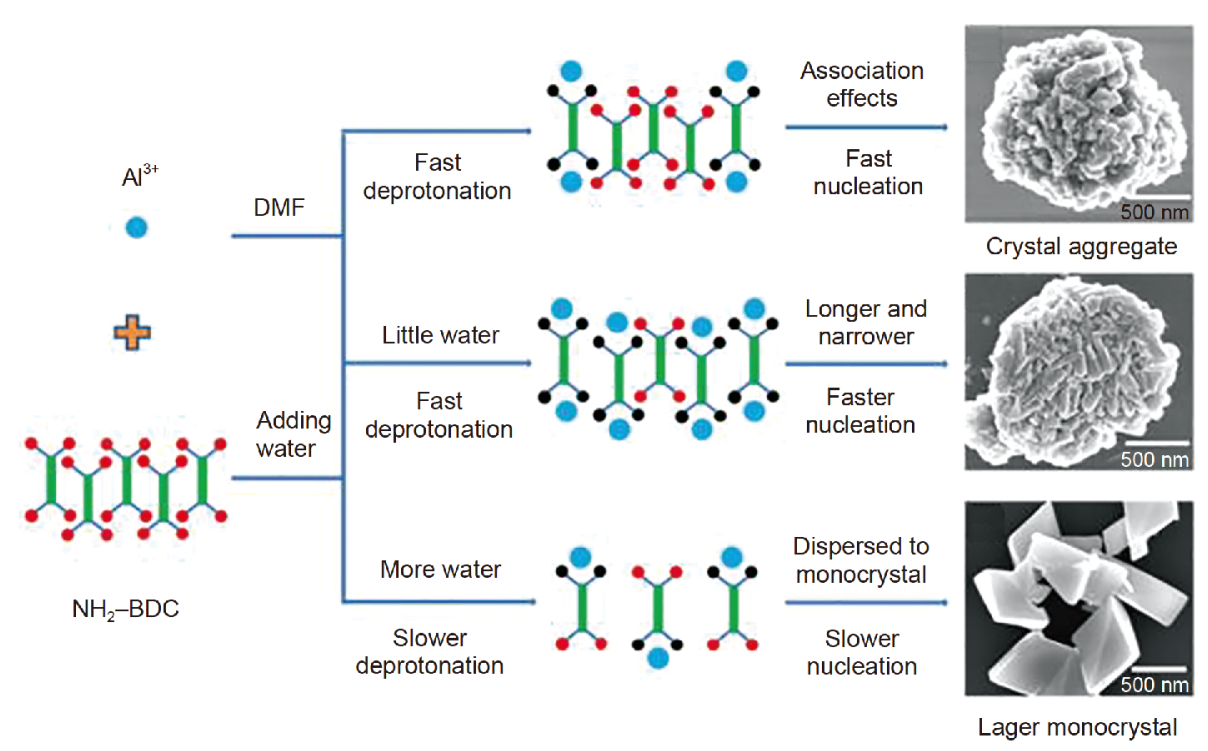

Figure 6 Schematic illustration of the preparation of $\mathrm{NH}_{2}-\mathrm{MIL}-53(\mathrm{Al})$ nanocrystals obtained from different solvents. Reprinted with permission from Ref. [115]. Copyright 2013, Royal Society of Chemistry. 
cently published studies showed that MIL-91, MIL-96 and MIL-160 can also be synthesized under water-based conditions [119-122]. From the examples given above, a certain amount of $\mathrm{NaOH}$ must be added to the synthesis system, which poses challenges in terms of the waste handling and disposal [123].

In addition to these, well-known MIL MOFs such as MIL-53 and MIL-100 can be synthesized in an aqueous solution [124,125]. Reinsch et al. [126] reported the water-based synthesis of a new Al-MOF (Al-MIL-68-Mes) that contained a Kagome-like framework structure with two different channels, using a short aliphatic methylfumaric acid $\left(\mathrm{H}_{2} \mathrm{Mes}\right)$ as a linker molecule. As shown in Fig. 7a, PXRD result confirmed that the as-synthesized Al-MIL-68-Mes crystal possessed a Kagome-like MIL-68 framework structure having interconnection of chains of trans-corner sharing $\mathrm{AlO}_{6}$ polyhedra (in which $\mathrm{OH}$ groups act as $\mu$-connecting ligands) via $\mathrm{H}_{2} \mathrm{Mes}$ molecule in four directions. Accordingly, the formation of two channels with a large hexagonal channel (diameters: $\sim 6 \AA$ ) and small trigonal channel (diameters: $\sim 2 \AA$ ) could be observed, as shown in Fig. 7b. Moreover, the Al-MIL68-Mes showed a high BET specific surface area $\left(S_{\mathrm{BET}}=\right.$ $\left.1040 \mathrm{~m}^{2} \mathrm{~g}^{-1}\right)$ as well as excellent thermal and chemical stabilities (stable upon water and methanol vapor sorption).

Recently, some magnetic MOF composites have received tremendous attention because they combine the merits of each material [127]. For example, Huang et al. [128] reported the synthesis of magnetic Al-based MOFs composites (MFC-N) using organic salt $\left(\mathrm{NH}_{2}-\mathrm{Na}_{2} \mathrm{BDC}\right)$ as anionic ligand source and $\mathrm{Fe}_{3} \mathrm{O}_{4} @ \mathrm{SiO}_{2}$ magnetic nanoparticles (MNPs) as a magnetic substance in water at room temperature. The TEM image revealed that the assynthesized $\mathrm{Fe}_{3} \mathrm{O}_{4} @ \mathrm{SiO}_{2}$ MNPs possessed a typical coreshell structure with $\mathrm{Fe}_{3} \mathrm{O}_{4}$ as core and $\mathrm{SiO}_{2}$ as shell, as shown in Fig. 8a. Furthermore, the TEM image in Fig. 8b confirmed that a number of $\mathrm{Fe}_{3} \mathrm{O}_{4} @ \mathrm{SiO}_{2}$ MNPs with particle sizes of $\sim 15 \mathrm{~nm}$ were embedded into the MOF, and the two components can be clearly identified. The elemental mapping images indicated that the distributions of $\mathrm{C}, \mathrm{O}, \mathrm{Al}$, and $\mathrm{N}$ elements were homogeneous in MFC-N crystal (Fig. 8c). Additionally, the strong signal of $\mathrm{Fe}$ and $\mathrm{Si}$ elements also demonstrated that the MNPs were embedded into the frameworks of MOF crystals, as observed in Fig. 8c. The obtained MFC-N nanocrystals exhibited a high surface area, remarkable magnetic response, and excellent water and thermal stability, thereby possessing high adsorption capacities toward methylene blue $\left(358 \mathrm{mg} \mathrm{g}^{-1}\right)$ and $\mathrm{As}(\mathrm{V})\left(71 \mathrm{mg} \mathrm{g}^{-1}\right)$ from environmental water. Compared with conventional methods [129], this synthetic route successfully avoided the generation of a large amount of toxic and harmful corrosive acid such as $\mathrm{HNO}_{3}$ or $\mathrm{HCl}$. In addition, other examples of MIL MOFs synthesized in aqueous solutions are given in Table 1.

\section{UiO series}

Although MOFs commonly exhibit much weaker stability in comparison with conventional porous materials such as activated carbon and metal oxide [130-133], $\mathrm{UiO}$ family is an important branch of MOFs that has a high thermal and chemical stability in comparison with other MOFs [134]. Zirconium MOFs (Zr-MOFs) are one archetypical UiO-family that is based on 12-connected metal nodes and usually adopts face-centered cubic (fcu) network topology [135]. The original route for $\mathrm{Zr}-\mathrm{MOF}$ synthesis involves the use of DMF as the solvent, which generates a large amount of waste and by-product [136]. Fortunately, some recent studies have reported green synthesis routes using less hazardous solvents and reaction upscaling [137].
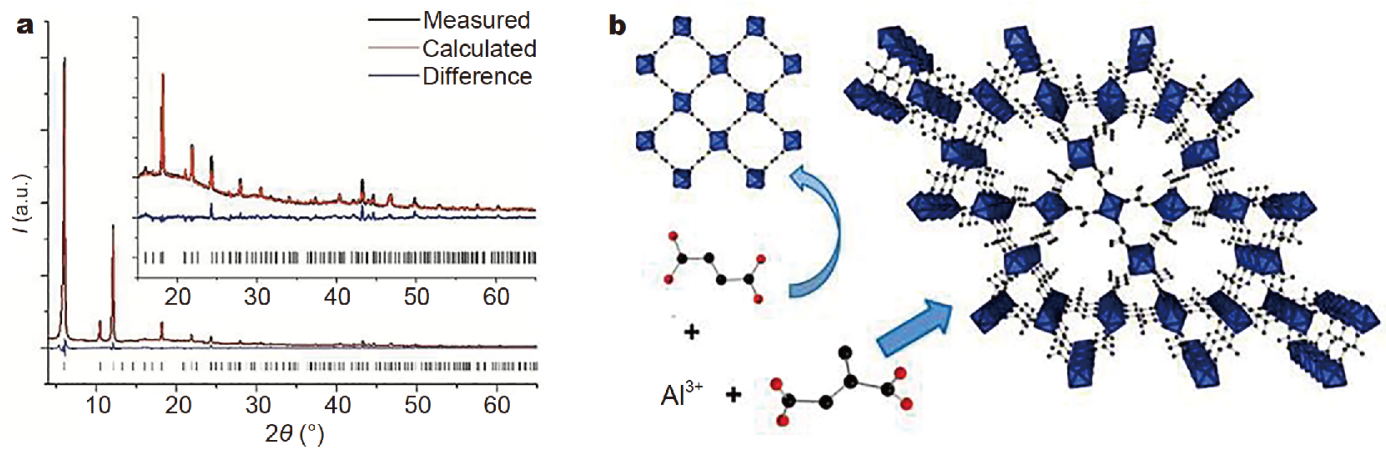

Figure 7 (a) XRD patterns of Al-MIL-68-Mes and the calculated data; (b) synthetic process of Al-MIL-68-Mes in an aqueous solution. Reprinted with permission from Ref. [126]. Copyright 2018, Wiley-VCH. 


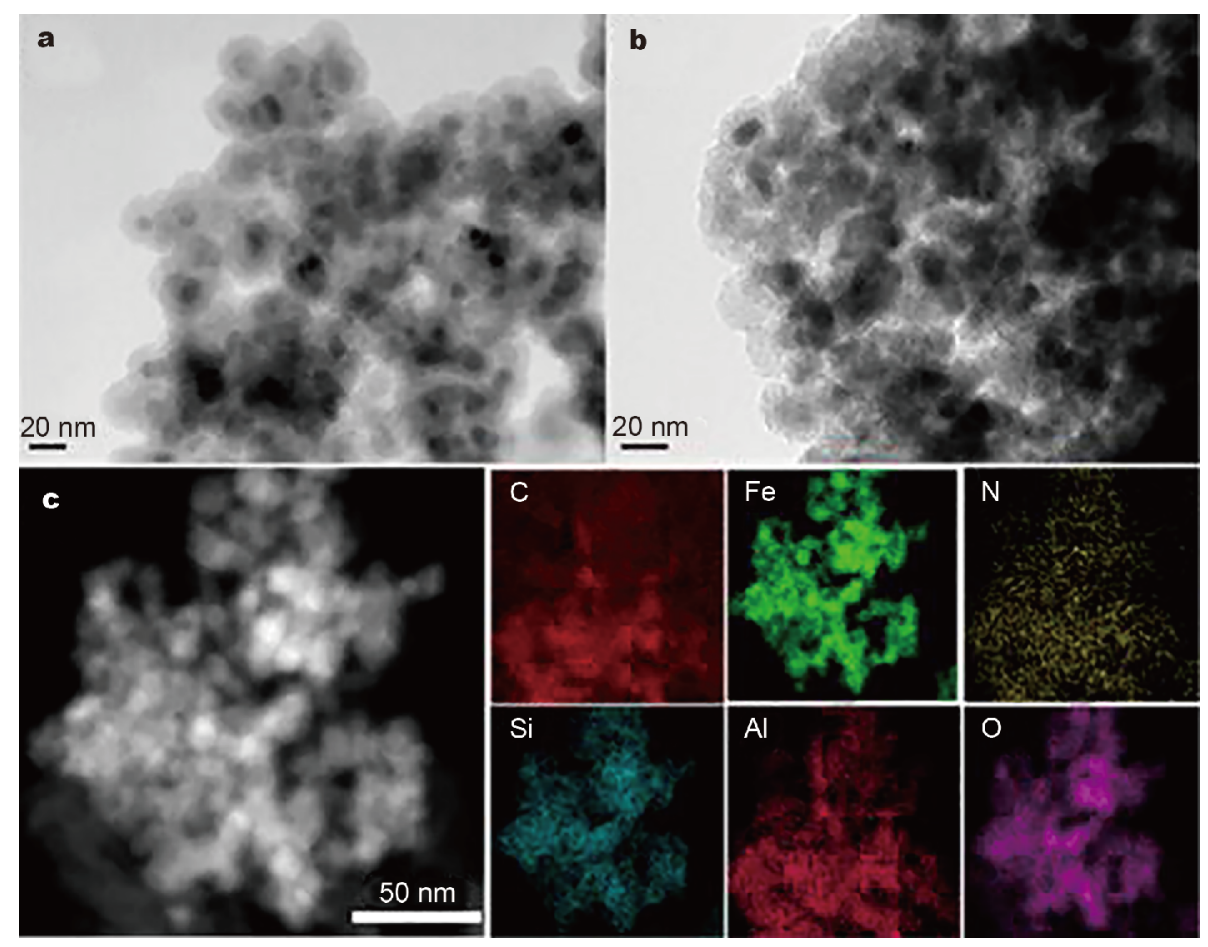

Figure 8 TEM images of (a) MNPs and (b) MFC-N-100 samples; (c) elemental mapping images of MFC-N-100. Reprinted with permission from Ref. [128]. Copyright 2018, ACS Publications.

Table 1 MOFs synthesized only using water as the solvent

\begin{tabular}{cccc}
\hline No. & MOFs & Synthesis conditions & Refs. \\
\hline 1 & MIL-34 & Water $\left(180^{\circ} \mathrm{C} / 10 \mathrm{~d}\right)$ & {$[177]$} \\
2 & MIL-69 & Water $\left(210^{\circ} \mathrm{C} / 16 \mathrm{~h}\right)$ & {$[178]$} \\
3 & MIL-88A & Water $\left(65^{\circ} \mathrm{C} / 2 \mathrm{~h}\right)$ & {$[179]$} \\
4 & MIL-91 & Water $\left(60^{\circ} \mathrm{C} / 0.5 \mathrm{~h}\right)$ & {$[180]$} \\
5 & MIL-96 & Water $\left(210^{\circ} \mathrm{C} / 24 \mathrm{~h}\right)$ & {$[181]$} \\
6 & MIL-100 & Water $\left(210^{\circ} \mathrm{C} / 5 \mathrm{~min}\right)$ & {$[182]$} \\
7 & MIL-110 & Water $\left(210^{\circ} \mathrm{C} / 15 \mathrm{~min}\right)$ & {$[182]$} \\
8 & MIL-118 & Water $\left(210^{\circ} \mathrm{C} / 24 \mathrm{~h}\right)$ & {$[183]$} \\
9 & MIL-121 & Water $\left(210^{\circ} \mathrm{C} / 24 \mathrm{~h}\right)$ & {$[184]$} \\
10 & MIL-127 & Water $\left(85^{\circ} \mathrm{C} / 24 \mathrm{~h}\right)$ & {$[185]$} \\
11 & MIL-129 & Water $\left(210^{\circ} \mathrm{C} / 24 \mathrm{~h}\right)$ & {$[186]$} \\
12 & MIL-140A & Water $\left(110^{\circ} \mathrm{C} / 24 \mathrm{~h}\right)$ & {$[187]$} \\
13 & CAU-11 & Water $\left(150^{\circ} \mathrm{C} / 12 \mathrm{~h}\right)$ & {$[188]$} \\
14 & CAU-12 & Water $\left(170^{\circ} \mathrm{C} / 5 \mathrm{~h}\right) \mathrm{MW}$ heating & {$[188]$} \\
15 & CAU-15 & Water $\left(100^{\circ} \mathrm{C} / 3 \mathrm{~h}\right) \mathrm{MW}$ heating & {$[189]$} \\
16 & CAU-28 & Water $\left(80^{\circ} \mathrm{C} / 1 \mathrm{~h}\right) \mathrm{MW}$ heating & {$[190]$} \\
17 & Al-PCP & Water $\left(180^{\circ} \mathrm{C} / 24 \mathrm{~h}\right)$ & {$[191]$} \\
18 & Al-PMOF & Water $\left(180^{\circ} \mathrm{C} / 16 \mathrm{~h}\right)$ & {$[192]$} \\
\hline
\end{tabular}

a) Microwave.
Zahn et al. [138] developed a simple method for the preparation of $\mathrm{Zr}$-fumarate MOFs from an aqueous system at different temperatures $\left(120^{\circ} \mathrm{C}\right.$ or room temperature) using monocarboxylic acids, such as formic acid, acetic acid, and propionic acid as modulators. The particle size of MOF crystals can be readily tuned by controlling the alkyl chain lengths of the modulating molecules. For example, SEM images confirmed that the crystal size became smaller as the alkyl chains of the modulators were longer (Fig. 9). The as-synthesized $\mathrm{Zr}$ fumarate MOFs exhibited a stable robust structure at $300^{\circ} \mathrm{C}$ and remained stable in organic solvents as well as acidic and alkaline conditions. Usually, MOF synthesized in water has a poor crystalline structure and/or a decreased porosity in comparison with that synthesized in organic solvents [139]. However, neither the crystallinity nor the porosity of the produced $\mathrm{Zr}$-fumarate MOFs was decreased. The BET surface area was $970 \mathrm{~m}^{2} \mathrm{~g}^{-1}$, which is comparable to that of $\mathrm{Zr}$-fumarate MOFs obtained in DMF $\left(1010 \mathrm{~m}^{2} \mathrm{~g}^{-1}\right)$ [140]. In addition, unlike Soxhlet extraction which involves the coercive removal of organic solvents from the pore system of MOFs [141], no additional purification steps were performed to activate the $\mathrm{Zr}$-fumarate MOFs. It should be noted that although the introduced monocarboxylic acid can serve as a modulator 

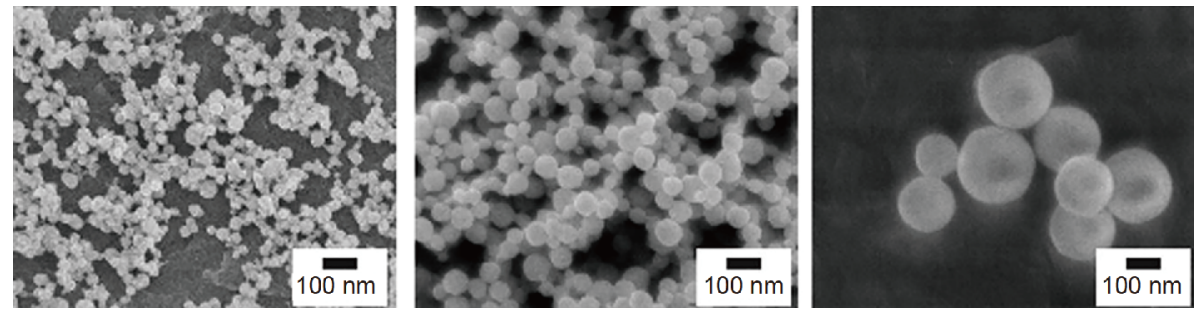

Figure 9 SEM images of Zr-fumarate MOF crystals synthesized under different reaction conditions. Reprinted with permission from Ref. [138]. Copyright 2015, Elsevier.

to increase the kinetics of the formation of inorganic nodes, additional modulator acid induces the risk of corrosion and increases the cost [142].

Generally, the reduction of synthesis temperatures to room temperature is more favorable in decreasing environmental impact and scale-up production due to the lower energy input required [10]. Pakamore et al. [143] developed an entirely facile and green approach for the ambient-temperature aqueous synthesis of UiO- $66-\mathrm{NH}_{2}$ using a disodium salt of 2-aminoterephthalic acid as a ligand and an aqueous solution of acetic acid as a modulator (Fig. 10). The resulting UiO-66- $\mathrm{NH}_{2}$ nanocrystals have a high BET specific surface area with a range of 845 to $888 \mathrm{~m}^{2} \mathrm{~g}^{-1}$, which is close to the product obtained by a conventional solvothermal method $\left(833.4 \mathrm{~m}^{2} \mathrm{~g}^{-1}\right)$. Moreover, the obtained nanocrystals demonstrate point defects due to the presence of dangling ligands, while a significant amount of missing ligands were not observed. Very recently, Chen et al. [144] also reported the roomtemperature synthesis of two $\mathrm{Zr}-\mathrm{MOFs}$ composed of $\mathrm{Zr}_{6}$ cluster nodes $\left(\mathrm{UiO}-66-(\mathrm{COOH})_{2}\right.$ and $\left.\mathrm{UiO}-66-\mathrm{F}_{4}\right)$ using a mixture of water and acetic acid as solvents. Notably, the mild synthesis conditions signify that the UiO-66$(\mathrm{COOH})_{2}$ can be reliably scaled-up from $30 \mathrm{mg}$ to $20 \mathrm{~g}$. These synthetic methods exclude the use of toxic solvents and minimize the energy requirements for the production of $\mathrm{Zr}-\mathrm{MOF}$, which are easy for scale-up [6].

Compared with the conventional hydrothermal method, microwave synthesis is a simple and rapid method [145]. Reinsch et al. [54] proposed a versatile green method for the scalable batch synthesis of diverse $\mathrm{Zr}$ MOFs by employing $\mathrm{ZrOCl}_{2} \cdot 8 \mathrm{H}_{2} \mathrm{O}$, acetic acid, water, and the respective ligand under microwave irradiation. They obtained five $\mathrm{Zr}$-MOFs at multigram scale with different topologies such as $\mathrm{UiO}-66-(\mathrm{OH})_{2}$, zirconium mesaconate, zirconium fumarate, MOF-808, and DUT-67. Unlike previous studies which did not report the porosity properties of the product [146], this microwave synthesis route suits the continuous production and also yields

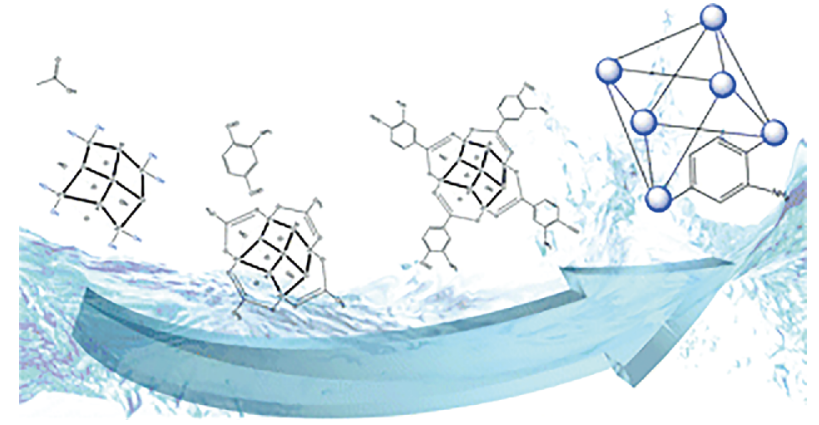

Figure 10 Diagram of room-temperature aqueous synthesis of $\mathrm{Zr}$ MOFs. Reprinted with permission from Ref. [143]. Copyright 2018, Royal Society of Chemistry.

compounds with high porosity and crystallinity. A followup study carried out by the same group reported the synthesis of two new Zr-MOFs (MIP-200 and CAU-39) in aqueous systems, using 2,5-pyrazinedicarboxylic acid $\left(\mathrm{H}_{2} \mathrm{PzDC}\right)$ and 4,4'-azopyridine-dicarboxylic acid $\left(\mathrm{H}_{2} \mathrm{APDC}\right)$ as ligands [147,148]. The as-synthesized CAU-22 possesses a unique one-dimensional (1D) inorganic building unit (IBU) of edge-sharing hexanuclear $\left(\mathrm{Zr}_{6} \mathrm{O}_{4}\left(\mathrm{OH}_{4}\right)\right)$ cluster while the obtained CAU-39 contains a $2 \mathrm{D}$ IBU of dodecanuclear $\left(\mathrm{M}_{12} \mathrm{O}_{8}(\mathrm{OH})_{14}\right)$ cluster.

During the water-based synthesis of $\mathrm{Zr}-\mathrm{MOFs}$ above, some modulators such as nitric or acetic acid have often been used to facilitate the growth of crystals by adjusting the reaction kinetics [149]. However, several recent studies focus on the use of acid modulators in $\mathrm{Zr}-\mathrm{MOFs}$ synthesis, while few studies focus on the role of acidity of between modulator feature and product performance [142]. Hu et al. [150] did pioneering work on the study of the behaviors of modulator and ligand. They comprehensively and quantitatively investigated the effects of modulator parameters (acidity and amount) and synthetic conditions on the properties of the resulting UiO66-type products synthesized in water. The results showed that the crystallinity, pore size, morphology, de- 
fects, stability, yield, and adsorption performance of the resulting UiO-66-type MOFs depend on the modulators. Furthermore, some semiempirical models can be obtained by analyzing the obtained data, where a relationship between the optimal molar ratio $(y)$ and acidity value $\left(\mathrm{p} K_{\mathrm{a}}\right)$ of modulator $x$ is given as $y=12.72+0.193 \times$ $\exp (1.276 x)$. Moreover, the synthesis of $\mathrm{Zr}-\mathrm{MOF}$ using ligands with different acidities tends to follow the equations of $y=-40.78+39.1 x$ and $y=-21.7+25.58 x$ for acetic acid and formic acid, respectively. In general, these semi-rational formulas are very useful in quantitative analysis and synthetic guidelines for the future trials of water-based production of MOFs.

In addition to conventional microporous $\mathrm{Zr}-\mathrm{MOFs}$, mesoporous $\mathrm{Zr}-\mathrm{MOF}$ can also be synthesized in aqueous solutions. A common SDA was used as a template to guide the formation of mesopores and macropores in MOFs [151,152]. Li et al. [74] developed the template synthesis of mesoporous $\mathrm{UiO}-66-\mathrm{NH}_{2}$. They reported a facile water-based template strategy for the direct synthesis of hierarchical micro- and mesoporous Zr-based MOFs. As shown in Fig. 11, the introduced amphoteric surfactant self-assembled and formed rod-shaped micelles. Meanwhile, the carboxylate groups of template micelles provided a coordinating agent that chemically anchored to the metal precursor. The ligand then selfassembled with a metal precursor in the presence of template micelles for framework formation. Besides, mesopores were formed after the removal of template molecules. The dimensions of mesopores were readily tuned by controlling the alkyl chain length of the template. However, the stability of the produced mesopores did not reduce in the resulting mesoporous $\mathrm{Zr}-\mathrm{MOF}$. The use of amphoteric templates in the synthesis of mesoporous $\mathrm{UiO}$ MOFs introduces a new method to allow rational tuning of the porosity by controlling the length of surfactant used. Very recently, Niu et al. [153] reported the synthesis of two hierarchical porous $\mathrm{Zr}-\mathrm{MOF}$ (UiO66 and UiO-66- $\mathrm{NH}_{2}$ ) using a free-template strategy. The as-synthesized hierarchical porous $\mathrm{UiO}-66$ and UiO-66$\mathrm{NH}_{2}$ have smaller nanoparticles $(<100 \mathrm{~nm})$ and exhibit enhanced adsorption and catalytic performances.

To date, many effective methods have been proposed for the green and cheap synthesis of UiO MOFs. However, there are few reports on their large-scale production from kilogram $(\mathrm{kg})$ scale to commercialization at the ton (t) scale [6,55]. Recently, Karadeniz et al. [154] reported a green mechanochemical synthesis approach for the continuous production of a series of $\mathrm{Zr}-\mathrm{MOF}$ ( $\mathrm{UiO}-66$, UiO-66-- $\mathrm{NH}_{2}$, MOF-801 and MOF-804) using a non- conventional zirconium dodecanuclear acetate cluster and a small amount of water as the liquid-assisted grinding (LAG) additive. The synthesis can be scaled to a $10 \mathrm{~g}$ scale using a planetary mill, or to larger scales using continuous processing by a twin-screw extrusion (Fig. 12) to produce more than $100 \mathrm{~g}$ of $\mathrm{UiO}-66-\mathrm{NH}_{2}$ MOFs in a continuous process at a rate of ca. $1.4 \mathrm{~kg} \mathrm{~h}^{-1}$. The assynthesized Zr-MOFs exhibited high crystallinity, porosity, and stability so that there was no need for excessive workup (activation) or stabilization of the framework with DMF. This method is expected to realize the breakthrough of high-performance production of $\mathrm{Zr}-$ MOFs from the laboratory scale to industrial production. Another example of the green scalable synthesis of $\mathrm{Zr}$ MOFs was reported by Wang et al. [155], who reported a green and scalable method to synthesize a stable amino acid-based $\mathrm{Zr}$-MOFs (Zr-MIP-202) at reflux conditions. The STY of the obtained Zr-MIP-202 was as high as $7000 \mathrm{~kg} \mathrm{~m}^{-3}$ per day, which is higher than that of $\mathrm{Al}-$ MOFs currently being produced on ton scale $\left(>1000 \mathrm{~m}^{-3}\right.$ per day) [156]. Moreover, the author successfully realized the synthesis of Zr-MIP-202 at different scales, thereby providing the possibility of the green scalability of $\mathrm{Zr}-$ MOFs. The as-synthesized MIP-202(Zr) revealed excellent proton conductivity performances of $0.011 \mathrm{~S} \mathrm{~cm}^{-1}$ ( $363 \mathrm{~K}, 95 \%$ relative humidity (RH)). Relatively, the largescale synthesis of MOFs under reflux conditions can be achieved due to the facile preparation process [70].

\section{CPL series}

CPL series are constructed from neutral 2-D layers consisting of metal ions $\left(\mathrm{Cu}^{2+}\right)$ and ligands (pyrazine-2,3-

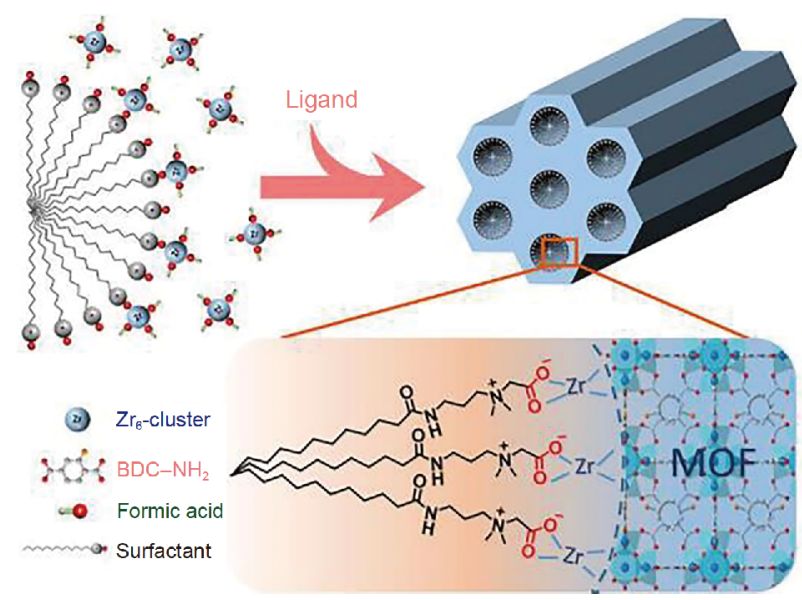

Figure 11 Schematic illustration of the construction of hexagonal mesoUiO-66- $\mathrm{NH}_{2}$ from an aqueous solution. Reprinted with permission from reference [74]. Copyright 2018, Wiley-VCH. 


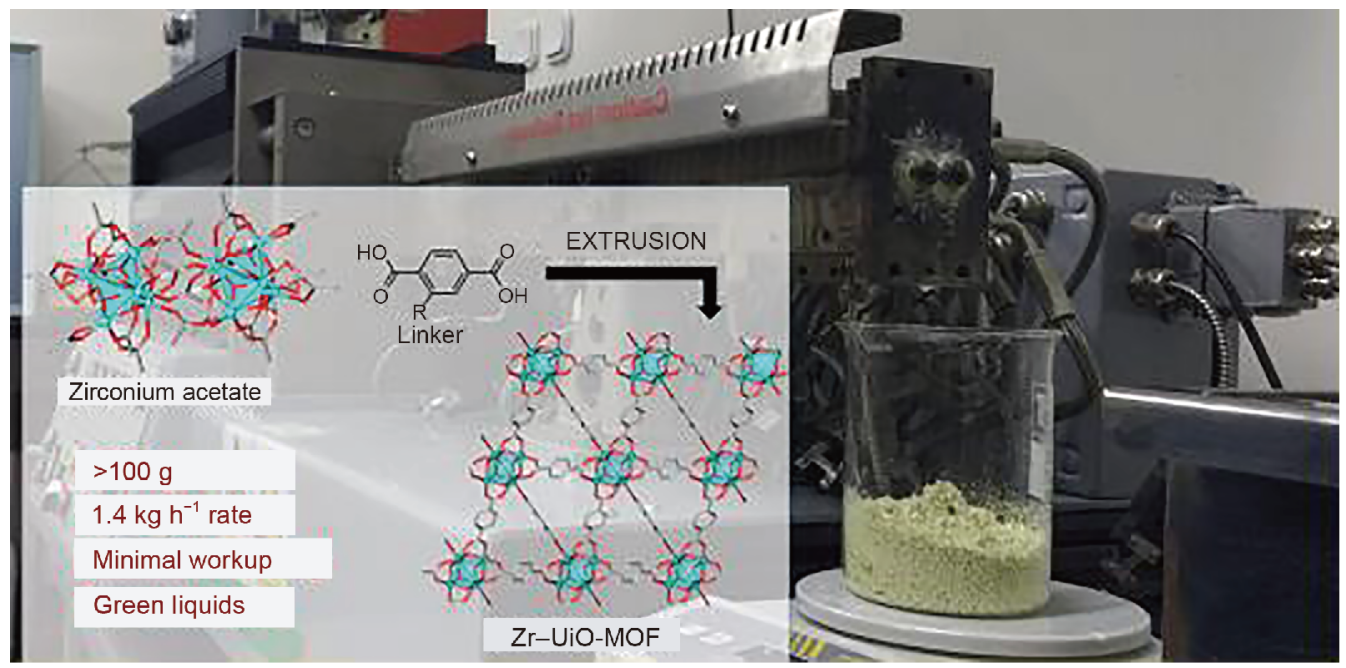

Figure 12 Twin-screw extrusion (TSE) setup used for the continuous mechanochemical fabrication of UiO-66- $\mathrm{NH}_{2} \mathrm{MOFs}_{\text {(extruded product was }}$ collected in a $1000 \mathrm{~mL}$ beaker). Reprinted with permission from Ref. [154]. Copyright 2018, ACS Publications.

dicarboxylate, pzdc) and separated by various pillar ligands (L). They can be rationally designed and synthesized by the judicious choice of their building blocks $[157,158]$. PCPs have many significant characteristics such as facile synthesis conditions (e.g., room temperature and ambient pressure) and flexible frameworks $[159,160]$.

Chen et al. [161] reported the successful preparation of CPL-1 $\left(\left[\left\{\left[\mathrm{Cu}_{2}(\mathrm{pzdc})_{2}(\mathrm{~L})\right] \cdot \mathrm{xH}_{2} \mathrm{O}\right\}_{n}\right]\right)$ through the reaction of $\mathrm{Cu}\left(\mathrm{ClO}_{4}\right)_{2} \cdot 6 \mathrm{H}_{2} \mathrm{O}$ with $\mathrm{Na}_{2}$ pzdc and pyrazine in aqueous solutions. The SEM result indicates that the obtained CPL comprised of a $2 \mathrm{D}$ sheet of $\left[\{\mathrm{Cu}(\mathrm{pzdc})\}_{n}\right]$ and pillar pyrazine linkers that bridge each sheet of thickness $\sim 7.5 \AA$ (Fig. 13). Moreover, the thermogravimetric analysis (TGA) result reveals that the as-synthesized CPL-1 product has a good thermostability that can remain stable at $260^{\circ} \mathrm{C}$. Importantly, CPL- 1 is a flexible material that has a unique guest-responsive nature [162]. Chen et al. [161] systematically investigated the adsorption and separation of olefin/paraffin mixtures $\left(\mathrm{C}_{3} \mathrm{H}_{6} / \mathrm{C}_{3} \mathrm{H}_{8}\right)$ on flexible CPL1. The results indicated that the CPL-1 captured $\mathrm{C}_{3} \mathrm{H}_{6}$ rather than $\mathrm{C}_{3} \mathrm{H}_{8}$ owing to the gate-opening effect. Furthermore, the gate-opening pressure of $\mathrm{C}_{3} \mathrm{H}_{6}$ adsorption onto CPL-1 increased when the operating temperature increased from 273 to $288 \mathrm{~K}$.

In comparison with conventional solvothermal syntheses, mechanochemical methods have significant advantages for the large-scale production of MOFs such as lower cost, more safety, easy operation, efficient reaction rate, and high selectivity. Furthermore, they do not consider the solubility of reactants $[163,164]$. Sakamoto et al.

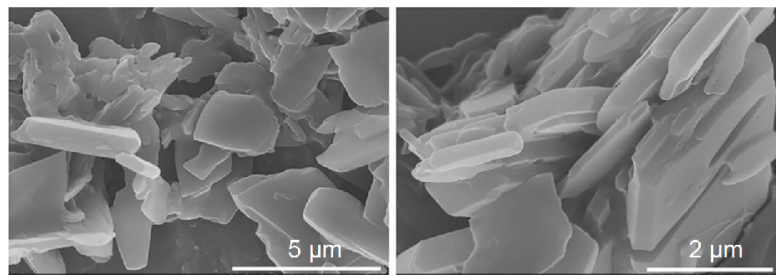

Figure 13 The SEM images of CPL-1 synthesized from aqueous solutions. Reprinted with permission from Ref. [162]. Copyright 2017, Elsevier.

[165] reported the preparation of CPL-1 by a mechanochemical method in humid conditions without organic solvents. Moreover, a series of other CPLs (CPL-2, 3, 4, 5, and 15) can also be synthesized by a similar process using different pillar ligands (Fig. 14), even if some pillar ligands are almost insoluble in water, thereby indicating the universality of such mechanochemical methods. During the mechanochemical process, the added water plays a vital role because it serves as material transporters and accelerates the diffusion of the species in inter- and intraparticle fashion.

\section{PCN series}

PCNs are a vital branch of MOFs that have many outstanding chemical and physical properties [82,166]. Although a large number of PCNs have been fabricated using various methods, to the best of our knowledge, no reported PCNs have been synthesized in pure aqueous systems. PCN syntheses involve the dissolution of most insoluble ligands that require a large amount of organic 


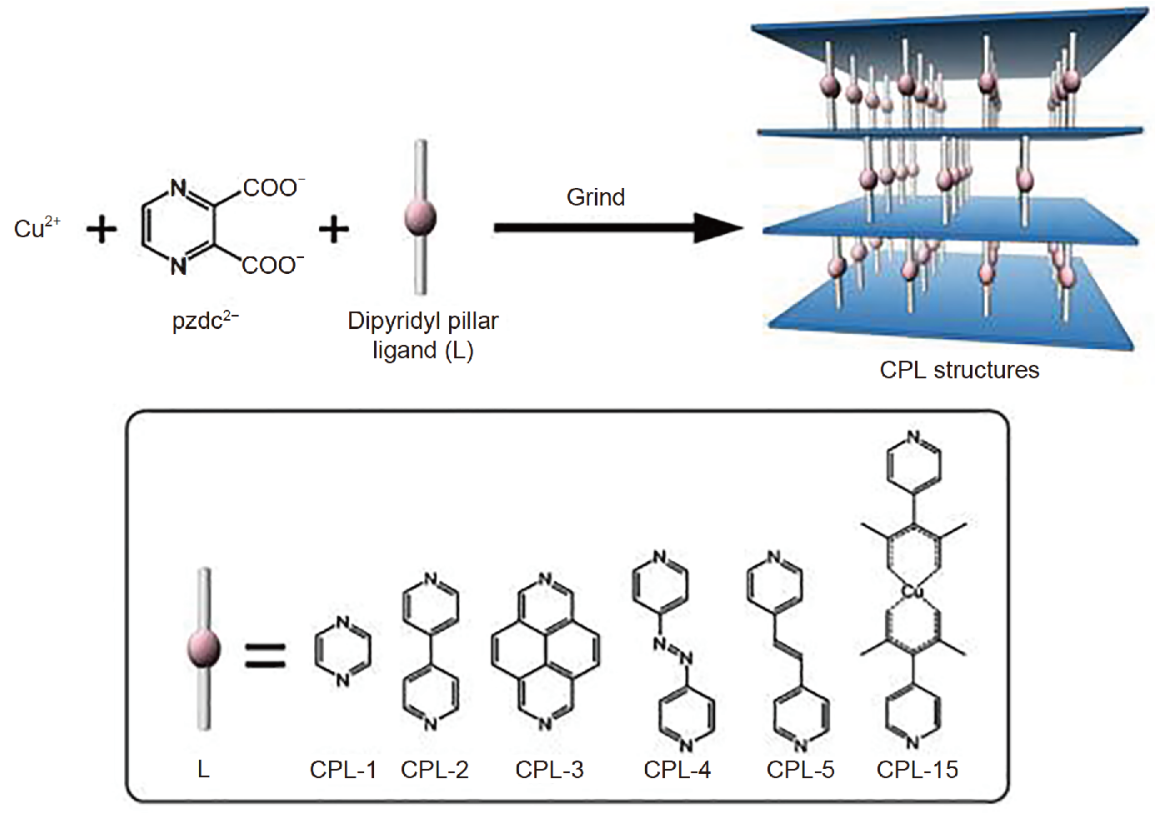

Figure 14 Schematic illustration of mechanochemical synthesis of a series of CPLs. Reprinted with permission from Ref. [165]. Copyright 2012, Royal Society of Chemistry.

solvents such as DMF, $N, N$-diethylformamide (DEF), and $N, N^{\prime}$-dimethylacetamide (DMA) to ensure the entire dissolution of PCN precursors $[167,168]$. Over the past decades, several investigations on PCNs have focused on $\mathrm{H}_{2}$ storage [169], small molecules (e.g., $\mathrm{CH}_{4}, \mathrm{CO}_{2}, \mathrm{CO}$, $\mathrm{N}_{2}$, and $\mathrm{O}_{2}$ ) adsorption $[170,171]$, and chemiresistive sensors [172]. However, based on the environmental and economic factors, the heavy use of organic solvents hinders the industrial exploitation of PCNs [173]. Therefore, the switch from organic solvents to aqueous solution is significant to reducing environmental and economic impacts for the future large-scale industrial production of PCNs.

Usually, a kind of synthetic method was developed for a certain type of MOFs [52,174]. However, some special synthetic strategies have been developed to synthesize different types of MOFs in aqueous solutions. For example, Sánchez-Sánchez et al. [174] reported the waterbased synthesis of a number of MOFs at room temperature by employing organic salts as anionic building blocks, including MOF-5, MOF-74, MIL-100(Fe) and MIL-53-Al-X (X = H, $\left.\mathrm{NH}_{2}, \mathrm{NO}_{2}\right)$. Similarly, Avci-Camur et al. [175] have described the water-based synthesis of two types of MOFs (Zr-MOFs and MIL MOFs) using metal acetylacetonate complexes as alternative source of metals. Most recently, Jacobsen et al. [176] reported the successful water-based syntheses of a series of $\mathrm{Ce}_{(\mathrm{IV})^{-}}$
MOFs (UiO-66, CAU-41 and CAU-44) with three different topologies (fcu, body-centered cubic (bcu), and body-centered tetragonal (bct)) within $30 \mathrm{~min}$ via microwave-assisted reactions using six chiral and achiral alkane dicarboxylic $\mathrm{C}_{4}$-acids as ligands. In general, the development of a versatile method to fabricate different types of MOFs for future large-scale industrial production is desirable but challenging. In addition to the familiar MOFs that have already been synthesized using green chemistry, other examples of MOFs synthesized in aqueous solutions have also been reported, some of which are summarized in Table 1.

\section{CONCLUSIONS AND OUTLOOK}

In general, avoiding the use of harmful solvents even in only a part of the synthesis procedure is remarkable progress at a practical synthesis level since the production, recycling or treatment of solvents are associated with a high cost and environmental pollution. In this review, we have highlighted recent advancements in the water-based synthesis strategies of MOFs and an emphasis on their green production. It is obvious that the water-based synthesis route possesses distinct advantages as a green method for the preparation of MOFs. They are cheap and much simpler, versatile, environmentally friendly, and with more easily post-treatable solvent, readily to scale-up and reduce the generation of harmful 
by-products $[51,144]$. However, it must be noted that some challenges and limitations still exist in the realization of large-scale industrial production of MOFs. For example, poor crystalline structure, decreased porosity, and low yields should not be overlooked in the resulting MOFs synthesized in aqueous solutions [193]. Furthermore, based on similarity-intermiscibility theory, many organic ligands are hardly soluble in water [194]. In addition, MOF synthesis is largely conducted in solvothermal or hydrothermal conditions, which usually requires a high temperature and pressure with long reaction time, as indicated by the examples above $[195,196]$. These severe reaction conditions are also known to consume a lot of energy and reduce the production rate (in general STYs are below $300 \mathrm{~kg} \mathrm{~m}^{-3}$ per day) $[55,197,198]$. In addition, in terms of green applications, a crucial pre-requisite in the real world is the ability to achieve the low-cost synthesis of high-quality MOF materials in large quantities with high efficiency $[45,199,200]$. Based on the concept of "green synthesis of MOFs" proposed by Reinsch et al. [70] and Julien et al. [75], five evaluative criteria that illustrate how MOF industrial synthesis and application is turning toward greener and sustainable concepts are (1) using water or other non-toxicity or lowtoxicity solvents (e.g., ionic liquids) to replace toxic solvents in the synthesis and activation/purification process; (2) minimizing energy input and preferably the room temperature and pressures; (3) improving product yields and STYs, the maximization of incorporating raw material or feedstock to the resultant product and the minimum of the synthesis time; (4) avoiding the generation of additional by-product or waste (except water) and synthesis steps; (5) continuous manufacturing routes. Although all examples given above satisfy point (1) and few examples satisfy points (1) and (2), an effective synthesis route that can satisfy all the requirements of "green synthesis of MOFs" remains a current challenge.

The large-scale production of MOFs requires a low manufacturing cost and addresses the related safety hazards and environmental impacts. Thus, the application of the principles of "green synthesis" in the preparation of MOFs is central to their industrial productions and commercial applications. In recent years, although great achievements have been made in the water-based preparation of MOF materials, an available method that achieves the level of "green synthesis" has been hardly reported. This means that the concept of "green synthesis of MOFs" is still at its infancy since other synthesis conditions such as room temperature and ambient pressures, high product yields and STYs have not yet been considered. Therefore, the exploration of advanced synthesis routes to reach the level of "green synthesis" is urgent for the future industrial production of MOFs. This realization, by both industry and academia, will be one of the most significant steps toward truly implementing MOF commercialization.

Received 2 October 2019; accepted 6 February 2020;

published online 27 March 2020

1 Abednatanzi S, Gohari Derakhshandeh P, Depauw H, et al. Mixed-metal metal-organic frameworks. Chem Soc Rev, 2019, 48: 2535-2565

2 Ding M, Flaig RW, Jiang HL, et al. Carbon capture and conversion using metal-organic frameworks and MOF-based materials. Chem Soc Rev, 2019, 48: 2783-2828

3 Szuromi P. Mesoporous metal-organic frameworks. Science, 2018, 359: 172.9-173

4 Shen K, Zhang L, Chen X, et al. Ordered macro-microporous metal-organic framework single crystals. Science, 2018, 359: 206210

5 Dhakshinamoorthy A, Li Z, Garcia H. Catalysis and photocatalysis by metal organic frameworks. Chem Soc Rev, 2018, 47: 8134-8172

6 Wang S, Serre C. Toward green production of water-stable metalorganic frameworks based on high-valence metals with low toxicities. ACS Sustain Chem Eng, 2019, 7: 11911

7 Li H, Eddaoudi M, O'Keeffe M, et al. Design and synthesis of an exceptionally stable and highly porous metal-organic framework. Nature, 1999, 402: 276-279

8 Yin W, Tao C, Wang F, et al. Tuning optical properties of MOFbased thin films by changing the ligands of mofs. Sci China Mater, 2018, 61: 391-400

9 Bai Y, Dou Y, Xie LH, et al. Zr-based metal-organic frameworks: Design, synthesis, structure, and applications. Chem Soc Rev, 2016, 45: 2327-2367

10 Duan C, Huo J, Li F, et al. Ultrafast room-temperature synthesis of hierarchically porous metal-organic frameworks by a versatile cooperative template strategy. J Mater Sci, 2018, 53: 16276-16287

11 Liu S, Sun L, Xu F, et al. Nanosized Cu-MOFs induced by graphene oxide and enhanced gas storage capacity. Energy Environ Sci, 2013, 6: 818-823

12 Connolly BM, Aragones-Anglada M, Gandara-Loe J, et al. Tuning porosity in macroscopic monolithic metal-organic frameworks for exceptional natural gas storage. Nat Commun, 2019, 10: 2345

13 Silva P, Vilela SMF, Tomé JPC, et al. Multifunctional metalorganic frameworks: From academia to industrial applications. Chem Soc Rev, 2015, 44: 6774-6803

14 Guo Y, Peng X. Mass transport through metal organic framework membranes. Sci China Mater, 2019, 62: 25-42

15 Jiang K, Zhang L, Xia T, et al. A water-stable fcu-MOF material with exposed amino groups for the multi-functional separation of small molecules. Sci China Mater, 2019, 62: 1315-1322

16 Li L, Lin RB, Krishna R, et al. Ethane/ethylene separation in a metal-organic framework with iron-peroxo sites. Science, 2018, 362: 443-446

17 Duan C, Yu Y, Yang P, et al. Engineering new defects in MIL-100 (Fe) via a mixed-ligand approach to effect enhanced volatile organic compound adsorption capacity. Ind Eng Chem Res, 2020, 
59: 774-782

18 Li F, Zheng K, Zhang $\mathrm{H}$, et al. Nanoscale hierarchically porous metal-organic frameworks: Facile synthesis, mechanism research, and application. ACS Sustain Chem Eng, 2019, 7: 11080-11087

19 Li P, Modica JA, Howarth AJ, et al. Toward design rules for enzyme immobilization in hierarchical mesoporous metalorganic frameworks. Chem, 2016, 1: 154-169

20 Lian X, Chen YP, Liu TF, et al. Coupling two enzymes into a tandem nanoreactor utilizing a hierarchically structured MOF. Chem Sci, 2016, 7: 6969-6973

21 Zhao Y, Liu J, Horn M, et al. Recent advancements in metal organic framework based electrodes for supercapacitors. Sci China Mater, 2018, 61: 159-184

22 AlKaabi K, Wade CR, Dincă M. Transparent-to-dark electrochromic behavior in naphthalene-diimide-based mesoporous MOF-74 analogs. Chem, 2016, 1: 264-272

23 Yang Q, Liu Y, Xiao L, et al. Self-templated transformation of MOFs into layered double hydroxide nanoarrays with selectively formed $\mathrm{Co}_{9} \mathrm{~S}_{8}$ for high-performance asymmetric supercapacitors. Chem Eng J, 2018, 354: 716-726

24 Wang B, Xie LH, Wang X, et al. Applications of metal-organic frameworks for green energy and environment: New advances in adsorptive gas separation, storage and removal. Green Energy Environ, 2018, 3: 191-228

25 Connolly BM, Mehta JP, Moghadam PZ, et al. From synthesis to applications: Metal-organic frameworks for an environmentally sustainable future. Curr Opin Green Sustain Chem, 2018, 12: 4756

26 Lu G, Hupp JT. Metal-organic frameworks as sensors: A ZIF-8 based Fabry-Perot device as a selective sensor for chemical vapors and gases. J Am Chem Soc, 2010, 132: 7832-7833

27 Qiu S, Zhu G. Molecular engineering for synthesizing novel structures of metal-organic frameworks with multifunctional properties. Coord Chem Rev, 2009, 253: 2891-2911

28 Xue DX, Wang Q, Bai J. Amide-functionalized metal-organic frameworks: Syntheses, structures and improved gas storage and separation properties. Coord Chem Rev, 2019, 378: 2-16

29 Wang Z, Hu S, Yang J, et al. Nanoscale Zr-based MOFs with tailorable size and introduced mesopore for protein delivery. Adv Funct Mater, 2018, 28: 1707356

30 Wu MX, Yang YW. Metal-organic framework (MOF)-based drug/cargo delivery and cancer therapy. Adv Mater, 2017, 29: 1606134

31 Tran UPN, Le KKA, Phan NTS. Expanding applications of metalorganic frameworks: Zeolite imidazolate framework ZIF-8 as an efficient heterogeneous catalyst for the Knoevenagel reaction. ACS Catal, 2011, 1: 120-127

32 Li PZ, Aranishi K, Xu Q. Zif-8 immobilized nickel nanoparticles: Highly effective catalysts for hydrogen generation from hydrolysis of ammonia borane. Chem Commun, 2012, 48: 3173-3175

33 Tang F, Wang L, Zhang G, et al. Creating coordination mismatch in MOFs: Tuning from pore structure of the derived supported catalysts to their catalytic performance. Ind Eng Chem Res, 2019, 58: 5543-5551

34 Zhang $\mathrm{H}$, Huo J, Yang $\mathrm{H}$, et al. Green and rapid preparation of hierarchically porous metal-organic zeolites and simulation of their growth. J Mater Chem A, 2019, 7: 1022-1029

35 Stock N, Biswas S. Synthesis of metal-organic frameworks (MOFs): Routes to various mof topologies, morphologies, and composites. Chem Rev, 2012, 112: 933-969
Qiu LG, Xu T, Li ZQ, et al. Hierarchically micro- and mesoporous metal-organic frameworks with tunable porosity. Angew Chem Int Ed, 2008, 47: 9487-9491

37 Gao X, Wang Y, Ji G, et al. One-pot synthesis of hierarchical-pore metal-organic frameworks for drug delivery and fluorescent imaging. CrystEngComm, 2018, 20: 1087-1093

38 Li F, Zheng K, Zheng X, et al. Facile synthesis of hierarchical micro-mesoporous HKUST-1 using organic silane surfactant as a novel template. ChemistrySelect, 2019, 4: 2079-2083

39 Capello C, Fischer U, Hungerbühler K. What is a green solvent? A comprehensive framework for the environmental assessment of solvents. Green Chem, 2007, 9: 927-934

40 Mukherjee S, Ganguly S, Chakraborty A, et al. Green synthesis of self assembled nanospherical dysprosium MOFs: Selective and efficient detection of picric acid in aqueous and gas phase. ACS Sustain Chem Eng, 2019, 7: 819-830

41 Cox B G, Garcia-Rosas J, Schneider H. Solvent dependence of the stability of cryptate complexes. J Am Chem Soc, 1981, 103: 13841389

42 Petkovic M, Seddon KR, Rebelo LPN, et al. Ionic liquids: A pathway to environmental acceptability. Chem Soc Rev, 2011, 40: 1383-1403

43 Katz MJ, Brown ZJ, Colón YJ, et al. A facile synthesis of UiO-66, UiO-67 and their derivatives. Chem Commun, 2013, 49: 94499451

44 Simon MO, Li CJ. Green chemistry oriented organic synthesis in water. Chem Soc Rev, 2012, 41: 1415-1427

45 Rubio-Martinez M, Avci-Camur C, Thornton AW, et al. New synthetic routes towards MOF production at scale. Chem Soc Rev, 2017, 46: 3453-3480

46 Czaja AU, Trukhan N, Müller U. Industrial applications of metalorganic frameworks. Chem Soc Rev, 2009, 38: 1284-1293

47 Ajoyan Z, Marino P, Howarth AJ. Green applications of metalorganic frameworks. CrystEngComm, 2018, 20: 5899-5912

48 Bux H, Liang F, Li Y, et al. Zeolitic imidazolate framework membrane with molecular sieving properties by microwave-assisted solvothermal synthesis. J Am Chem Soc, 2009, 131: 1600016001

49 Seoane B, Zamaro JM, Tellez C, et al. Sonocrystallization of zeolitic imidazolate frameworks (ZIF-7, ZIF-8, ZIF-11 and Zif20). CrystEngComm, 2012, 14: 3103-3107

$50 \mathrm{Hu} \mathrm{L}$, Chen L, Fang Y, et al. Facile synthesis of zeolitic imidazolate framework-8 (ZIF-8) by forming imidazole-based deep eutectic solvent. Microporous Mesoporous Mater, 2018, 268: 207-215

51 Cadot S, Veyre L, Luneau D, et al. A water-based and high spacetime yield synthetic route to MOF $\mathrm{Ni}_{2}(\mathrm{dhtp})$ and its linker 2,5dihydroxyterephthalic acid. J Mater Chem A, 2014, 2: 1775717763

52 Crawford D, Casaban J, Haydon R, et al. Synthesis by extrusion: Continuous, large-scale preparation of MOFs using little or no solvent. Chem Sci, 2015, 6: 1645-1649

53 Garcia Marquez A, Horcajada P, Grosso D, et al. Green scalable aerosol synthesis of porous metal-organic frameworks. Chem Commun, 2013, 49: 3848-3850

54 Reinsch H, Waitschat S, Chavan SM, et al. A facile "green" route for scalable batch production and continuous synthesis of zirconium MOFs. Eur J Inorg Chem, 2016, 2016(27): 4490-4498

55 Benítez A, Amaro-Gahete J, Esquivel D, et al. Mil-88a metalorganic framework as a stable sulfur-host cathode for long-cycle 
Li-S batteries. Nanomater, 2020, 10: 424

56 Chen Y, Li S, Pei X, et al. A solvent-free hot-pressing method for preparing metal-organic-framework coatings. Angew Chem Int Ed, 2016, 55: 3419-3423

57 Kubo M, Saito T, Shimada M. Evaluation of the parameters utilized for the aerosol-assisted synthesis of HKUST-1. Microporous Mesoporous Mater, 2017, 245: 126-132

58 Baláž $\mathrm{P}$, Achimovičová $\mathrm{M}$, Baláž $\mathrm{M}$, et al. Hallmarks of mechanochemistry: From nanoparticles to technology. Chem Soc Rev, 2013, 42: 7571

59 Zhuang JL, Ceglarek D, Pethuraj S, et al. Rapid room-temperature synthesis of metal-organic framework HKUST-1 crystals in bulk and as oriented and patterned thin films. Adv Funct Mater, 2011, 21: $1442-1447$

60 Gaab M, Trukhan N, Maurer S, et al. The progression of Al-based metal-organic frameworks-From academic research to industrial production and applications. Microporous Mesoporous Mater, 2012, 157: 131-136

61 Sadat SA, Ghaedi AM, Panahimehr M, et al. Rapid room-temperature synthesis of cadmium zeolitic imidazolate framework nanoparticles based on 1,1'-carbonyldiimidazole as ultra-highefficiency adsorbent for ultrasound-assisted removal of malachite green dye. Appl Surf Sci, 2019, 467-468: 1204-1212

62 James SL, Adams CJ, Bolm C, et al. Mechanochemistry: Opportunities for new and cleaner synthesis. Chem Soc Rev, 2012, 41: 413-447

63 Bradshaw D, El-Hankari S, Lupica-Spagnolo L. Supramolecular templating of hierarchically porous metal-organic frameworks. Chem Soc Rev, 2014, 43: 5431-5443

$64 \mathrm{Na}$ L, Zhang L, Zhang W, et al. Rapid room-temperature synthesis of $\mathrm{Cu}_{3}(\mathrm{BTC})_{2}$ crystals in water. Synthesis Reactivity Inorg Metal-Org Nano-Metal Chem, 2015, 45: 1463-1466

65 Burtch NC, Jasuja H, Walton KS. Water stability and adsorption in metal-organic frameworks. Chem Rev, 2014, 114: 10575-10612

66 Li P, Chen J, Zhang J, et al. Water stability and competition effects toward $\mathrm{CO}_{2}$ adsorption on metal organic frameworks. Separation Purification Rev, 2015, 44: 19-27

67 Chou LY, Hu P, Zhuang J, et al. Formation of hollow and mesoporous structures in single-crystalline microcrystals of metalorganic frameworks via double-solvent mediated overgrowth. Nanoscale, 2015, 7: 19408-19412

68 Zhang J, White GB, Ryan MD, et al. Dihydrolevoglucosenone (cyrene) as a green alternative to $\mathrm{N}, \mathrm{N}$-dimethylformamide (DMF) in MOF synthesis. ACS Sustain Chem Eng, 2016, 4: 7186-7192

69 Parnham ER, Morris RE. Ionothermal synthesis of zeolites, metalorganic frameworks, and inorganic-organic hybrids. Acc Chem Res, 2007, 40: 1005-1013

70 Reinsch H. "Green" synthesis of metal-organic frameworks. Eur J Inorg Chem, 2016, 2016(27): 4290-4299

71 Lim B, Xiong Y, Xia Y. A water-based synthesis of octahedral, decahedral, and icosahedral pd nanocrystals. Angew Chem Int Edit, 2007, 46: 9279-9282

72 Ren J, Dyosiba X, Musyoka NM, et al. Review on the current practices and efforts towards pilot-scale production of metal-organic frameworks (MOFs). Coord Chem Rev, 2017, 352: 187-219

73 Garzón-Tovar L, Carné-Sánchez A, Carbonell C, et al. Optimised room temperature, water-based synthesis of CPO-27-M metalorganic frameworks with high space-time yields. J Mater Chem A, 2015, 3: 20819-20826

74 Li K, Lin S, Li Y, et al. Aqueous-phase synthesis of mesoporous
Zr-based MOFs templated by amphoteric surfactants. Angew Chem, 2018, 130: 3497-3501

75 Julien PA, Mottillo C, Friščić T. Metal-organic frameworks meet scalable and sustainable synthesis. Green Chem, 2017, 19: 27292747

76 Zhang H, Huo J, Li F, et al. Rapid synthesis of hierarchical porous metal-organic frameworks and the simulation of growth. Cryst Growth Des, 2018, 18: 6661-6669

77 Duan C, Zhang H, Yang M, et al. Templated fabrication of hierarchically porous metal-organic frameworks and simulation of crystal growth. Nanoscale Adv, 2019, 1: 1062-1069

78 Duan C, Yu Y, Li F, et al. Ultrafast room-temperature synthesis of hierarchically porous metal-organic frameworks with high spacetime yields. CrystEngComm, 2020, doi: 10.1039/C9CE01676G

79 Moghadam PZ, Li A, Wiggin SB, et al. Development of a cambridge structural database subset: A collection of metal-organic frameworks for past, present, and future. Chem Mater, 2017, 29: 2618-2625

80 Chen Z, Hanna SL, Redfern LR, et al. Reticular chemistry in the rational synthesis of functional zirconium cluster-based MOFs. Coord Chem Rev, 2019, 386: 32-49

81 Zhou HC, Kitagawa S. Metal-organic frameworks (MOFs). Chem Soc Rev, 2014, 43: 5415-5418

82 Janiak C, Vieth JK. MOFs, MILs and more: Concepts, properties and applications for porous coordination networks (PCNs). New J Chem, 2010, 34: 2366-2388

83 Jhung SH, Khan NA, Hasan Z. Analogous porous metal-organic frameworks: Synthesis, stability and application in adsorption. CrystEngComm, 2012, 14: 7099-7109

84 Phan A, Doonan CJ, Uribe-Romo FJ, et al. Synthesis, structure, and carbon dioxide capture properties of zeolitic imidazolate frameworks. Acc Chem Res, 2010, 43: 58-67

85 Li L, Duan Y, Liao S, et al. Adsorption and separation of propane/ propylene on various ZIF-8 polymorphs: Insights from GCMC simulations and the ideal adsorbed solution theory (IAST). Chem Eng J, 2020, 386: 123945

86 Park KS, Ni Z, Côté AP, et al. Exceptional chemical and thermal stability of zeolitic imidazolate frameworks. Proc Natl Acad Sci USA, 2006, 103: 10186-10191

87 Liang J, Liang Z, Zou R, et al. Heterogeneous catalysis in zeolites, mesoporous silica, and metal-organic frameworks. Adv Mater, 2017, 29: 1701139

88 Pan Y, Liu Y, Zeng G, et al. Rapid synthesis of zeolitic imidazolate framework-8 (ZIF-8) nanocrystals in an aqueous system. Chem Commun, 2011, 47: 2071-2073

89 Pan Y, Heryadi D, Zhou F, et al. Tuning the crystal morphology and size of zeolitic imidazolate framework-8 in aqueous solution by surfactants. CrystEngComm, 2011, 13: 6937-6940

90 Kida K, Okita M, Fujita K, et al. Formation of high crystalline ZIF-8 in an aqueous solution. CrystEngComm, 2013, 15: 17941801

91 Huang H, Li JR, Wang K, et al. An in situ self-assembly template strategy for the preparation of hierarchical-pore metal-organic frameworks. Nat Commun, 2015, 6: 8847

92 Gross AF, Sherman E, Vajo JJ. Aqueous room temperature synthesis of cobalt and zinc sodalite zeolitic imidizolate frameworks. Dalton Trans, 2012, 41: 5458-5460

93 Tian YQ, Zhao YM, Chen ZX, et al. Design and generation of extended zeolitic metal-organic frameworks (ZMOFs): Synthesis and crystal structures of zinc(II) imidazolate polymers with 
zeolitic topologies. Chem Eur J, 2007, 13: 4146-4154

94 Nordin NAHM, Ismail AF, Mustafa A, et al. Aqueous room temperature synthesis of zeolitic imidazole framework 8 (ZIF-8) with various concentrations of triethylamine. RSC Adv, 2014, 4: 33292-33300

95 Fan X, Wang W, Li W, et al. Highly porous ZIF-8 nanocrystals prepared by a surfactant mediated method in aqueous solution with enhanced adsorption kinetics. ACS Appl Mater Interfaces, 2014, 6: 14994-14999

96 Kaur G, Rai RK, Tyagi D, et al. Room-temperature synthesis of bimetallic $\mathrm{Co}-\mathrm{Zn}$ based zeolitic imidazolate frameworks in water for enhanced $\mathrm{CO}_{2}$ and $\mathrm{H}_{2}$ uptakes. J Mater Chem A, 2016, 4: 14932-14938

97 Lou X, Ning Y, Li C, et al. Bimetallic zeolite imidazolate framework for enhanced lithium storage boosted by the redox participation of nitrogen atoms. Sci China Mater, 2018, 61: 1040-1048

98 Eddaoudi M, Kim J, Rosi N, et al. Systematic design of pore size and functionality in isoreticular MOFs and their application in methane storage. Science, 2002, 295: 469-472

99 Tranchemontagne DJ, Hunt JR, Yaghi OM. Room temperature synthesis of metal-organic frameworks: MOF-5, MOF-74, MOF177, MOF-199, and IRMOF-0. Tetrahedron, 2008, 64: 8553-8557

100 Duan C, Li F, Luo S, et al. Facile synthesis of hierarchical porous metal-organic frameworks with enhanced catalytic activity. Chem Eng J, 2018, 334: 1477-1483

101 Yue Y, Fulvio PF, Dai S. Hierarchical metal-organic framework hybrids: Perturbation-assisted nanofusion synthesis. Acc Chem Res, 2015, 48: 3044-3052

102 Huo J, Brightwell M, El Hankari S, et al. A versatile, industrially relevant, aqueous room temperature synthesis of HKUST-1 with high space-time yield. J Mater Chem A, 2013, 1: 15220-15223

103 Siew WY, Abu Bakar NHH, Abu Bakar M. The influence of green synthesis on the formation of various copper benzene-1,3,5-tricarboxylate compounds. Inorg Chim Acta, 2018, 482: 53-61

104 Majano G, Pérez-Ramírez J. Scalable room-temperature conversion of copper(II) hydroxide into HKUST-1 $\left(\mathrm{Cu}_{3}(\mathrm{btc})_{2}\right)$. Adv Mater, 2013, 25: 1052-1057

105 Barros BS, de Lima Neto OJ, de Oliveira Frós AC, et al. Metalorganic framework nanocrystals. ChemistrySelect, 2018, 3: 74597471

106 Didriksen T, Spjelkavik AI, Blom R. Continuous synthesis of the metal-organic framework CPO-27-Ni from aqueous solutions. J Flow Chem, 2017, 7: 13-17

107 Julien PA, Užarević K, Katsenis $\mathrm{AD}$, et al. In situ monitoring and mechanism of the mechanochemical formation of a microporous MOF-74 framework. J Am Chem Soc, 2016, 138: 2929-2932

108 Yuan B, Wang X, Zhou X, et al. Novel room-temperature synthesis of MIL-100(Fe) and its excellent adsorption performances for separation of light hydrocarbons. Chem Eng J, 2019, 355: 679-686

109 Hamon L, Serre C, Devic T, et al. Comparative study of hydrogen sulfide adsorption in the MIL-53 (Al, Cr, Fe), MIL-47(V), MIL$100(\mathrm{Cr})$, and MIL-101(Cr) metal-organic frameworks at room temperature. J Am Chem Soc, 2009, 131: 8775-8777

110 Férey G, Latroche M, Serre C, et al. Hydrogen adsorption in the nanoporous metal-benzenedicarboxylate $\mathrm{M}(\mathrm{OH})\left(\mathrm{O}_{2} \mathrm{C}-\mathrm{C}_{6} \mathrm{H}_{4}\right.$ $\left.\mathrm{CO}_{2}\right)\left(\mathrm{M}=\mathrm{Al}^{3+}, \mathrm{Cr}^{3+}\right)$, MIL-53. Chem Commun, 2003, 2976-2977

111 Wack J, Siegel R, Ahnfeldt T, et al. Identifying selective host-guest interactions based on hydrogen bond donor-acceptor pattern in functionalized Al-MIL-53 metal-organic frameworks. J Phys
Chem C, 2013, 117: 19991-20001

112 Biswas S, Ahnfeldt T, Stock N. New functionalized flexible AlMIL-53-X (X = $\left.-\mathrm{Cl},-\mathrm{Br},-\mathrm{CH}_{3},-\mathrm{NO}_{2},-(\mathrm{OH})_{2}\right)$ solids: Syntheses, characterization, sorption, and breathing behavior. Inorg Chem, 2011, 50: 9518-9526

113 Férey G, Serre C. Large breathing effects in three-dimensional porous hybrid matter: Facts, analyses, rules and consequences. Chem Soc Rev, 2009, 38: 1380

114 Schneemann A, Bon V, Schwedler I, et al. Flexible metal-organic frameworks. Chem Soc Rev, 2014, 43: 6062-6096

115 Cheng X, Zhang A, Hou K, et al. Size- and morphology-controlled $\mathrm{NH}_{2}-\mathrm{MIL}-53(\mathrm{Al})$ prepared in DMF-water mixed solvents. Dalton Trans, 2013, 42: 13698-13705

116 Guan Y, Xia M, Wang X, et al. Water-based preparation of nanosized $\mathrm{NH}_{2}$-MIL-53(Al) frameworks for enhanced dye removal. Inorg Chim Acta, 2019, 484: 180-184

117 Yang $\mathrm{Y}$, Wang $\mathrm{W}$, Li $\mathrm{H}$, et al. $\mathrm{NH}_{2}-\mathrm{MIL}-53(\mathrm{Al})$ nanocrystals anchored on the surface of RGO hollow spheres and its visible light degradation of methylene blue. Mater Lett, 2017, 197: 17-20

118 Jung KW, Choi BH, Lee SY, et al. Green synthesis of aluminumbased metal organic framework for the removal of azo dye acid black 1 from aqueous media. J Industrial Eng Chem, 2018, 67: 316-325

119 Cadiau A, Lee JS, Damasceno Borges D, et al. Metal organic framework: Design of hydrophilic metal organic framework water adsorbents for heat reallocation (adv. Mater. 32/2015). Adv Mater, 2015, 27: 4803

120 Pillai RS, Jobic H, Koza MM, et al. Diffusion of carbon dioxide and nitrogen in the small-pore titanium bis (phosphonate) metalorganic framework MIL-91 (Ti): A combination of quasielastic neutron scattering measurements and molecular dynamics simulations. ChemPhysChem, 2017, 18: 2739-2746

121 Benoit V, Chanut N, Pillai RS, et al. A promising metal-organic framework (MOF), MIL-96( $\mathrm{Al})$, for $\mathrm{CO}_{2}$ separation under humid conditions. J Mater Chem A, 2018, 6: 2081-2090

122 Permyakova A, Skrylnyk O, Courbon E, et al. Synthesis optimization, shaping, and heat reallocation evaluation of the hydrophilic metal-organic framework MIL-160(Al). ChemSusChem, 2017, 10: 1419-1426

123 Bobbitt NS, Mendonca ML, Howarth AJ, et al. Metal-organic frameworks for the removal of toxic industrial chemicals and chemical warfare agents. Chem Soc Rev, 2017, 46: 3357-3385

124 Bauer S, Serre C, Devic T, et al. High-throughput assisted rationalization of the formation of metal organic frameworks in the iron(III) aminoterephthalate solvothermal system. Inorg Chem, 2008, 47: 7568-7576

125 Jhung S, Lee JH, Yoon J, et al. Microwave synthesis of chromium terephthalate MIL-101 and its benzene sorption ability. Adv Mater, 2007, 19: 121-124

126 Reinsch H, Homburg T, Heidenreich N, et al. Green synthesis of a new Al-MOF based on the aliphatic linker mesaconic acid: Structure, properties and in situ crystallisation studies of Al-MIL68-Mes. Chem Eur J, 2018, 24: 2173-2181

127 Ke F, Qiu LG, Yuan YP, et al. $\mathrm{Fe}_{3} \mathrm{O}_{4} @ \mathrm{MOF}$ core-shell magnetic microspheres with a designable metal-organic framework shell. J Mater Chem, 2012, 22: 9497-9500

128 Huang L, Cai J, He M, et al. Room-temperature synthesis of magnetic metal-organic frameworks composites in water for efficient removal of methylene blue and $\mathrm{As}(\mathrm{V})$. Ind Eng Chem Res, 2018, 57: 6201-6209 
129 Sanchez-Sanchez M, de Asua I, Ruano D, et al. Direct synthesis, structural features, and enhanced catalytic activity of the basolite F300-like semiamorphous Fe-BTC framework. Cryst Growth Des, 2015, 15: 4498-4506

130 Duan C, Cao Y, Hu L, et al. Synergistic effect of $\mathrm{TiF}_{3}$ on the dehydriding property of $\alpha-\mathrm{AlH}_{3}$ nano-composite. Mater Lett, 2019, 238: 254-257

131 Duan JA, Dong X, Yin K, et al. A hierarchical superaerophilic cone: Robust spontaneous and directional transport of gas bubbles. Appl Phys Lett, 2018, 113: 203704

132 Bian C, Zhang C, Pan S, et al. Generalized high-temperature synthesis of zeolite catalysts with unpredictably high space-time yields (stys). J Mater Chem A, 2017, 5: 2613-2618

133 Li L, Xiang S, Cao S, et al. A synthetic route to ultralight hierarchically micro/mesoporous $\mathrm{Al}(\mathrm{III})$-carboxylate metal-organic aerogels. Nat Commun, 2013, 4: 1774

134 Zhuang S, Cheng R, Wang J. Adsorption of diclofenac from aqueous solution using $\mathrm{UiO}-66$-type metal-organic frameworks. Chem Eng J, 2019, 359: 354-362

135 Cavka JH, Jakobsen S, Olsbye U, et al. A new zirconium inorganic building brick forming metal organic frameworks with exceptional stability. J Am Chem Soc, 2008, 130: 13850-13851

136 Devic T, Serre C. High valence $3 p$ and transition metal based mofs. Chem Soc Rev, 2014, 43: 6097-6115

137 Chen Z, Wang X, Islamoglu T, et al. Green synthesis of a functionalized zirconium-based metal-organic framework for water and ethanol adsorption. Inorganics, 2019, 7: 56

138 Zahn G, Schulze HA, Lippke J, et al. A water-born Zr-based porous coordination polymer: Modulated synthesis of $\mathrm{Zr}$-fumarate MOF. Microporous Mesoporous Mater, 2015, 203: 186-194

139 Senkovska I, Hoffmann F, Fröba M, et al. New highly porous aluminium based metal-organic frameworks: $\mathrm{Al}(\mathrm{OH})(\mathrm{ndc})$ (ndc=2,6-naphthalene dicarboxylate) and $\mathrm{Al}(\mathrm{OH})(\mathrm{bpdc})$ (bpdc $=4,4$ '-biphenyl dicarboxylate). Microporous Mesoporous Mater, 2009, 122: 93-98

140 Wißmann G, Schaate A, Lilienthal S, et al. Modulated synthesis of $\mathrm{Zr}$-fumarate MOF. Microporous Mesoporous Mater, 2012, 152: 64-70

$141 \mathrm{Xu} \mathrm{Y,} \mathrm{Yu} \mathrm{Q,} \mathrm{Zhao} \mathrm{D,} \mathrm{et} \mathrm{al.} \mathrm{Synthesis} \mathrm{and} \mathrm{characterization} \mathrm{of}$ porphyrin-based porous coordination polymers obtained by supercritical $\mathrm{CO}_{2}$ extraction. J Mater Sci, 2018, 53: 10534-10542

142 Schaate A, Roy P, Godt A, et al. Modulated synthesis of Zr-based metal-organic frameworks: From nano to single crystals. Chem Eur J, 2011, 17: 6643-6651

143 Pakamorè I, Rousseau J, Rousseau C, et al. An ambient-temperature aqueous synthesis of zirconium-based metal-organic frameworks. Green Chem, 2018, 20: 5292-5298

144 Chen Z, Wang X, Noh H, et al. Scalable, room temperature, and water-based synthesis of functionalized zirconium-based metalorganic frameworks for toxic chemical removal. CrystEngComm, 2019, 21: 2409-2415

145 Khan NA, Jhung SH. Synthesis of metal-organic frameworks (MOFs) with microwave or ultrasound: Rapid reaction, phaseselectivity, and size reduction. Coord Chem Rev, 2015, 285: 11-23

146 Ragon F, Chevreau H, Devic T, et al. Impact of the nature of the organic spacer on the crystallization kinetics of UiO-66(Zr)-type MOFs. Chem Eur J, 2015, 21: 7135-7143

147 Waitschat S, Reinsch H, Stock N. Water-based synthesis and characterisation of a new $\mathrm{Zr}$-MOF with a unique inorganic building unit. Chem Commun, 2016, 52: 12698-12701
148 Waitschat S, Reinsch H, Arpacioglu M, et al. Direct water-based synthesis and characterization of new $\mathrm{Zr} / \mathrm{Hf}-\mathrm{MOF}$ with dodecanuclear clusters as ibus. CrystEngComm, 2018, 20: 5108-5111

149 Waitschat S, Fröhlich D, Reinsch H, et al. Synthesis of M-UiO-66 $(\mathrm{M}=\mathrm{Zr}$, Ce Or Hf) employing 2,5-pyridinedicarboxylic acid as a linker: Defect chemistry, framework hydrophilisation and sorption properties. Dalton Trans, 2018, 47: 1062-1070

$150 \mathrm{Hu}$ Z, Castano I, Wang S, et al. Modulator effects on the waterbased synthesis of $\mathrm{Zr} / \mathrm{Hf}$ metal-organic frameworks: Quantitative relationship studies between modulator, synthetic condition, and performance. Cryst Growth Des, 2016, 16: 2295-2301

151 Duan C, Li F, Zhang H, et al. Template synthesis of hierarchical porous metal-organic frameworks with tunable porosity. RSC Adv, 2017, 7: 52245-52251

152 Duan C, Zhang H, Li F, et al. Hierarchically porous metal-organic frameworks: Rapid synthesis and enhanced gas storage. Soft Matter, 2018, 14: 9589-9598

153 Niu P, Lu N, Liu J, et al. Water-induced synthesis of hierarchical Zr-based MOFs with enhanced adsorption capacity and catalytic activity. Microporous Mesoporous Mater, 2019, 281: 92-100

154 Karadeniz B, Howarth AJ, Stolar T, et al. Benign by design: Green and scalable synthesis of zirconium UiO-metal-organic frameworks by water-assisted mechanochemistry. ACS Sustain Chem Eng, 2018, 6: 15841-15849

155 Wang S, Wahiduzzaman M, Davis L, et al. A robust zirconium amino acid metal-organic framework for proton conduction. Nat Commun, 2018, 9: 4937

156 Duan C, Li F, Li L, et al. Hierarchically structured metal-organic frameworks assembled by hydroxy double salt-template synergy with high space-time yields. CrystEngComm, 2018, 20: 10571064

157 Yaghi OM, O'Keeffe M, Ockwig NW, et al. Reticular synthesis and the design of new materials. Nature, 2003, 423: 705-714

158 Matsuda R, Kitaura R, Kitagawa S, et al. Guest shape-responsive fitting of porous coordination polymer with shrinkable framework. J Am Chem Soc, 2004, 126: 14063-14070

159 García-Ricard OJ, Hernández-Maldonado AJ. $\mathrm{Cu}_{2}$ (pyrazine-2,3dicarboxylate $)_{2}\left(4,4^{\prime}\right.$-bipyridine $)$ porous coordination sorbents: Activation temperature, textural properties, and $\mathrm{CO}_{2}$ adsorption at low pressure range. J Phys Chem C, 2010, 114: 1827-1834

160 Zheng F, Guo L, Gao B, et al. Engineering the pore size of pillared-layer coordination polymers enables highly efficient adsorption separation of acetylene from ethylene. ACS Appl Mater Interfaces, 2019, 11: 28197-28204

161 Chen Y, Qiao Z, Lv D, et al. Efficient adsorptive separation of $\mathrm{C}_{3} \mathrm{H}_{6}$ over $\mathrm{C}_{3} \mathrm{H}_{8}$ on flexible and thermoresponsive CPL-1. Chem Eng J, 2017, 328: 360-367

162 Kishida K, Watanabe Y, Horike S, et al. DRIFT and theoretical studies of ethylene/ethane separation on flexible and microporous $\left[\mathrm{Cu}_{2}(2,3 \text {-pyrazinedicarboxylate })_{2} \text { (pyrazine) }\right]_{n}$. Eur J Inorg Chem, 2014, 2014(17): 2747-2752

163 Li Y, Miao J, Sun X, et al. Mechanochemical synthesis of $\mathrm{Cu}-$ BTC@Go with enhanced water stability and toluene adsorption capacity. Chem Eng J, 2016, 298: 191-197

164 Chen $\mathrm{Y}, \mathrm{Wu} \mathrm{H}$, Liu Z, et al. Liquid-assisted mechanochemical synthesis of copper based MOF-505 for the separation of $\mathrm{CO}_{2}$ over $\mathrm{CH}_{4}$ or $\mathrm{N}_{2}$. Ind Eng Chem Res, 2018, 57: 703-709

165 Sakamoto H, Matsuda R, Kitagawa S. Systematic mechanochemical preparation of a series of coordination pillared layer frameworks. Dalton Trans, 2012, 41: 3956-3961 
Choi W, Ohtsu H, Matsushita $\mathrm{Y}$, et al. Safe $\mathrm{P}_{4}$ reagent in a reusable porous coordination network. Dalton Trans, 2016, 45: 6357-6360

167 Zhang M, Chen YP, Zhou HC. Structural design of porous coordination networks from tetrahedral building units. CrystEngComm, 2013, 15: 9544-9552

168 Haneda T, Kawano M, Kawamichi T, et al. Direct observation of the labile imine formation through single-crystal-to-single-crystal reactions in the pores of a porous coordination network. J Am Chem Soc, 2008, 130: 1578-1579

169 Wang XS, Ma S, Yuan D, et al. A large-surface-area boracitenetwork-topology porous MOF constructed from a conjugated ligand exhibiting a high hydrogen uptake capacity. Inorg Chem, 2009, 48: 7519-7521

170 Ozturk TN, Keskin S. Predicting gas separation performances of porous coordination networks using atomistic simulations. Ind Eng Chem Res, 2013, 52: 17627-17639

171 Braga D, Curzi M, Johansson A, et al. Simple and quantitative mechanochemical preparation of a porous crystalline material based on a $1 \mathrm{D}$ coordination network for uptake of small molecules. Angew Chem Int Ed, 2006, 45: 142-146

172 Kim J, Koo JY, Lee YH, et al. Structural investigation of chemiresistive sensing mechanism in redox-active porous coordination network. Inorg Chem, 2017, 56: 8735-8738

173 Sheldon RA. Green solvents for sustainable organic synthesis: State of the art. Green Chem, 2005, 7: 267-278

174 Sánchez-Sánchez M, Getachew N, Díaz K, et al. Synthesis of metal-organic frameworks in water at room temperature: Salts as linker sources. Green Chem, 2015, 17: 1500-1509

175 Avci-Camur C, Perez-Carvajal J, Imaz I, et al. Metal acetylacetonates as a source of metals for aqueous synthesis of metalorganic frameworks. ACS Sustain Chem Eng, 2018, 6: 1455414560

176 Jacobsen J, Achenbach B, Reinsch H, et al. The first water-based synthesis of $\mathrm{Ce}(\mathrm{IV})-\mathrm{MOF}$ with saturated chiral and achiral $\mathrm{C}_{4}$ dicarboxylate linkers. Dalton Trans, 2019, 48: 8433-8441

177 Loiseau T, Mellot-Draznieks C, Sassoye C, et al. Chemistrystructure-simulation or chemistry-simulation-structure sequences? The case of MIL-34, a new porous aluminophosphate. J Am Chem Soc, 2001, 123: 9642-9651

178 Loiseau T, Mellot-Draznieks C, Muguerra H, et al. Hydrothermal synthesis and crystal structure of a new three-dimensional aluminum-organic framework MIL-69 with 2,6-naphthalenedicarboxylate (ndc), $\mathrm{Al}(\mathrm{OH})(\mathrm{ndc}) \cdot \mathrm{H}_{2} \mathrm{O}$. Comptes Rendus Chimie, 2005, 8: 765-772

179 Horcajada P, Chalati T, Serre C, et al. Porous metal-organicframework nanoscale carriers as a potential platform for drug delivery and imaging. Nat Mater, 2010, 9: 172-178

180 Benoit V, Pillai RS, Orsi A, et al. MIL-91(Ti), a small pore metalorganic framework which fulfils several criteria: an upscaled green synthesis, excellent water stability, high $\mathrm{CO}_{2}$ selectivity and fast $\mathrm{CO}_{2}$ transport. J Mater Chem A, 2016, 4: 1383-1389

181 Loiseau T, Lecroq L, Volkringer C, et al. MIL-96, a porous aluminum trimesate $3 \mathrm{D}$ structure constructed from a hexagonal network of 18 -membered rings and $\mu_{3}$-oxo-centered trinuclear units. J Am Chem Soc, 2006, 128: 10223-10230

182 Khan NA, Lee JS, Jeon J, et al. Phase-selective synthesis and phase-conversion of porous aluminum-benzenetricarboxylates with microwave irradiation. Microporous Mesoporous Mater, 2012, 152: 235-239
183 Volkringer C, Loiseau T, Guillou N, et al. Structural transitions and flexibility during dehydration-rehydration process in the MOF-type aluminum pyromellitate $\mathrm{Al}_{2}(\mathrm{OH})_{2}\left[\mathrm{C}_{10} \mathrm{O}_{8} \mathrm{H}_{2}\right]$ (MIL118). Cryst Growth Des, 2009, 9: 2927-2936

184 Volkringer C, Loiseau T, Guillou N, et al. High-throughput aided synthesis of the porous metal-organic framework-type aluminum pyromellitate, MIL-121, with extra carboxylic acid functionalization. Inorg Chem, 2010, 49: 9852-9862

185 Chevreau H, Permyakova A, Nouar F, et al. Synthesis of the biocompatible and highly stable MIL-127(Fe): From large scale synthesis to particle size control. CrystEngComm, 2016, 18: 4094-4101

186 Volkringer C, Loiseau T, Devic T, et al. A layered coordination polymer based on an azodibenzoate linker connected to aluminium (MIL-129). CrystEngComm, 2010, 12: 3225-3228

187 D'Amato R, Donnadio A, Carta M, et al. Water-based synthesis and enhanced $\mathrm{CO}_{2}$ capture performance of perfluorinated cerium-based metal-organic frameworks with UiO-66 and MIL-140 topology. ACS Sustain Chem Eng, 2019, 7: 394-402

188 Reimer N, Reinsch H, Inge AK, et al. New Al-MOFs based on sulfonyldibenzoate ions: A rare example of intralayer porosity. Inorg Chem, 2015, 54: 492-501

189 Heidenreich N, Lieb A, Stock N, et al. Green synthesis of a new layered aluminium citraconate: Crystal structures, intercalation behaviour towards $\mathrm{H}_{2} \mathrm{O}$ and in situ PXRD studies of its crystallisation. Dalton Trans, 2018, 47: 215-223

190 Dreischarf AC, Lammert M, Stock N, et al. Green synthesis of ZrCAU-28: Structure and properties of the first Zr-MOF based on 2,5-furandicarboxylic acid. Inorg Chem, 2017, 56: 2270-2277

191 Comotti A, Bracco S, Sozzani P, et al. Nanochannels of two distinct cross-sections in a porous al-based coordination polymer. J Am Chem Soc, 2008, 130: 13664-13672

192 Fateeva A, Chater PA, Ireland CP, et al. A water-stable porphyrinbased metal-organic framework active for visible-light photocatalysis. Angew Chem Int Ed, 2012, 51: 7440-7444

193 Woodley JM. New opportunities for biocatalysis: Making pharmaceutical processes greener. Trends Biotech, 2008, 26: 321-327

194 Zhang Y, Fu Q, Ge J. Photonic sensing of organic solvents through geometric study of dynamic reflection spectrum. Nat Commun, 2015, 6: 7510

195 Zhang H, Huo J, Li J, et al. Hierarchically porous metal-organic frameworks with single-crystal structures and their enhanced catalytic properties. CrystEngComm, 2018, 20: 5754-5759

196 Duan C, Zhang H, Peng A, et al. Synthesis of hierarchically structured metal-organic frameworks by a dual-functional surfactant. ChemistrySelect, 2018, 3: 5313-5320

197 Duan C, Yang M, Li F, et al. Soft-templating synthesis of mesoporous metal-organic frameworks with enhanced toluene adsorption capacity. ChemistrySelect, 2018, 3: 12888-12893

198 Evans JD, Garai B, Reinsch H, et al. Metal-organic frameworks in germany: From synthesis to function. Coord Chem Rev, 2019, 380: $378-418$

199 Reinsch H, Stock N. Synthesis of MOFs: A personal view on rationalisation, application and exploration. Dalton Trans, 2017, 46: 8339-8349

200 Yuan S, Feng L, Wang K, et al. Stable metal-organic frameworks: Design, synthesis, and applications. Adv Mater, 2018, 30: 1704303

Acknowledgements We gratefully acknowledge the financial support from the National Natural Science Foundation of China (21576094, 
21776097 and 51678245), Guangdong Natural Science Foundation (2017A030313052 and 2019A1515011121), Guangzhou Science \& Technology Project (201804010219), and the Fundamental Research Funds for the Central Universities.

Author contributions Original idea was conceived by Duan C, Yu Y, and Xi H. Manuscript was drafted by Duan C, Yu Y, Xiao J, Zhang X, Li $\mathrm{L}$, Yang $\mathrm{P}, \mathrm{Wu} \mathrm{J}$ and $\mathrm{Xi} \mathrm{H}$. All authors discussed and commented on the manuscript.

Conflict of interest The authors declare that they have no conflict of interest.

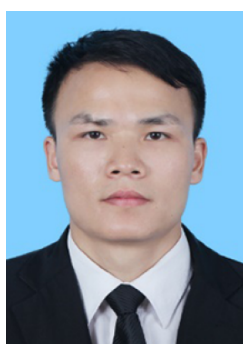

Chongxiong Duan received his $\mathrm{PhD}$ degree in chemical engineering from South China University of Technology in 2019. He is currently an associate professor at the School of Materials Science and Energy Engineering, Foshan University. His research interests include the synthesis and characterization of functional nanoporous materials (MOFs, zeolites), and green chemistry.

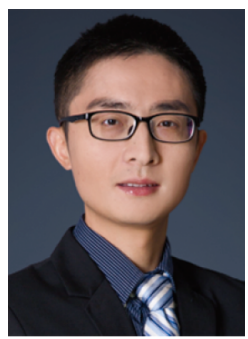

Junliang $\mathbf{W u}$ received his $\mathrm{PhD}$ degree in energy and environmental materials from South China University of Technology in 2014. He was a visiting scholar at the University of Massachusetts Amherst (2016-2017). He is currently an associate professor in environment engineering at South China University of Technology. His research concerns environmental materials and their applications.

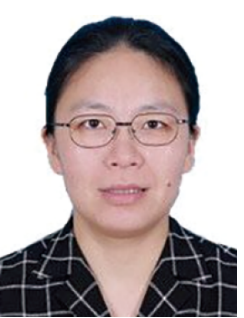

Hongxia Xi received her $\mathrm{PhD}$ degree in chemical engineering from South China University of Technology in 1996. She then worked as a post-doctor for two years at Sun Yat-sen Unviersity, as a visiting scholar for one year at Savoie University, France, and as a senior visiting scholar for six months at The State University of New Jersey, USA. She is currently a professor of chemical engineering at South China University of Technology. Her research materials and their applications.

interests focus on the development of porous

\section{金属-有机骨架材料水相合成路线研究进展}

段崇雄 ${ }^{1}$, 余仪 ${ }^{2}$, 肖静 ${ }^{2}$, 张雪莲 ${ }^{2}$, 李理波 ${ }^{2}$, 阳鹏飞 ${ }^{4}$, 吴军良 ${ }^{3 *}$, 奚红霞 ${ }^{2 *}$

摘要 金属-有机骨架材料具有优异的物理化学性质, 因而在气体 储存、吸附分离、药物传输、超级电容器、催化等领域具有广阔 的应用前景. 然而大多数金属-有机骨架材料的合成通常需要用到 大量的有机溶剂, 而这些有机溶剂的使用不仅会增加金属-有机骨 架材料的生产成本, 且极易对环境造成影响. 基于此, 理想的合成 路线是用水代替有害的有机溶剂, 以降低成本及减轻其对环境的 影响. 本文总结了近期金属-有机骨架材料水相合成路线的研究进 展, 重点概括了不同水相合成法制备金属-有机骨架材料的机理, 并分析了各种方法的优缺点. 此外, 还讨论了当前绿色且低成本工 业化生产金属-有机骨架材料存在的问题以及未来可能的发展方 向. 